\title{
Development of Septal Cholinergic Neurons in Culture: Plating Density and Glial Cells Modulate Effects of NGF on Survival, Fiber Growth, and Expression of Transmitter-Specific Enzymes
}

\author{
Jukka Hartikka and Franz Hefti \\ Department of Neurology, University of Miami School of Medicine, Miami, Florida 33101
}

To characterize the role of NGF in the development of forebrain cholinergic neurons, we establlshed primary cell culture systems to grow these cells under controlled in vitro conditions. Cultures of dissociated cells were prepared from the septal area of fetal (E17) rats, which contained part of the group of basal forebrain cholinergic neurons. Cultures were treated either with $\mathrm{NGF}(100 \mathrm{ng} / \mathrm{ml})$ or with an antiserum against NGF (1:500 dilution). To assess the influence of non-neuronal cells, 2 types of high-density cultures were prepared: mixed neuronal-glial cultures and pure neuronal cultures. Cholinergic neurons were identified using choline acetyltransferase (ChAT) immunocytochemistry and AChE cytochemistry. Receptors for NGF (NGF-R) were located immunocytochemically using monoclonal antibodies against rat NGF-R.

We report that, first, NGF-R are exclusively localized on cholinergic neurons in septal cultures. All neurons labeled with antibodies against NGF-R also contained AChE. Twenty-one percent of all AChE-positive neurons were not stained in NGF-R immunocytochemistry (AChE has earlier been shown to be colocalized with ChAT in septal cultures). Second, NGF treatment increases and anti-NGF treatment reduces the number of AChE-positive neurons in cultures of low plating density, suggesting that NGF promotes survival of septal cholinergic neurons in these cultures. In cultures of high plating density, NGF increased the number of NGF-R and ChAT-positive neurons without affecting the number of AChE-positive neurons in these cultures. These results suggest that exogenous NGF is not required for survival of cholinergic neurons in high-density cultures but stimulates the expression of ChAT and NGF-R. Third, NGF stimulates fiber growth of septal cholinergic neurons, as assessed by computerized image analysis of AChE-positive neurons. Fourth, NGF specifically increases ChAT and AChE activities in septal cultures. These NGF-mediated increases in enzyme activities are more pronounced when neurons are grown together with glial cells. In pure neuronal cultures, NGF increased ChAT and AChE activities by 101 and $16 \%$, and

\footnotetext{
Received Sept. 14, 1987; revised Dec. 10, 1987; accepted Dec. 10, 1987.

This work was supported by NIH Grant NS22933 and by grants from the Alzheimer's Disease and Related Disorders Association, Chicago (P-85-004), and the National Parkinson Foundation, Miami. We wish to thank Dr. J. N. Barrett for helpful discussions and advice.

Studies were done by J.H. in partial fulfilment of the requirements of a Ph.D. thesis, Department of Biochemistry, University of Basel, Switzerland.

Correspondence should be addressed to Di. F. Hefli, Department of Neurology, University of Miami, P. O. Box 016960, Miami, FL 33101.

Copyright (C) 1988 Society for Neuroscience $0270-6474 / 88 / 082967-19 \$ 02.00 / 0$
}

in mixed neuronal-glial cultures by 318 and $87 \%$, respectively. Anti-NGF blocked the effects of NGF but failed to reduce ChAT and AChE activities below control levels in cultures of high plating density. Fifth, astrocytes attenuate the expression of ChAT and AChE by septal neurons in the absence of NGF. In 10-d-old cultures, the number of AChEpositive cells was the same in pure neuronal cultures and in mixed neuronal-glial cultures, indicating that cholinergic neurons survive and differentiate in these cultures in the absence of astrocytes. ChAT and AChE activities per cholinergic neuron were approximately twice as high in untreated pure neuronal cultures than in mixed neuronal-glial cultures. However, NGF treatment stimulated ChAT activity to the same maximal level (approximately $170 \mathrm{fmol} / \mathrm{min} / \mathrm{cho}-$ linergic neuron) in both types of cultures. Finally, NGF increases the size of the cell body of cholinergic neurons. In 3-week-old mixed neuronal-glial cultures, approximately $\mathbf{9 0 \%}$ of the large neurons (diameter of the cell body 25-30 $\mu \mathrm{m}$ ) contained NGF-R and AChE. This observation will make it possible to reliably identify living cholinergic neurons in cell culture for electrophysiological studies.

NGF is the best-studied trophic factor involved in the regulation of neuronal development. Its role as a neurotrophic factor for peripheral sympathetic and sensory neurons has been extensively characterized (Thoenen and Barde, 1980; Levi-Montalcini, 1982; Yankncr and Shooter, 1982; Thoenen and Edgar, 1985). On the basis of findings obtained on sympathetic neurons, it was anticipated that NGF also affects catecholaminergic neurons of the CNS. Findings reported by several laboratories (Konkol et al., 1978; Schwab et al., 1979; Dreyfus et al., 1980) clearly demonstrated that central dopaminergic and noradrenergic neurons do not respond to NGF. However, results obtained in recent years indicate that NGF acts as a neurotrophic factor for basal forebrain cholinergic neurons. These neurons-which are located in medial septum, diagonal band of Broca, and nucleus basalis of Meynert - provide a widespread and topographically organized innervation to hippocampus and cortex (Mesulam et al., 1983b; Wainer et al., 1984; Woolf et al., 1984).

Several groups of findings show that NGF affects forebrain cholinergic neurons in the adult mammalian brain. First, NGF

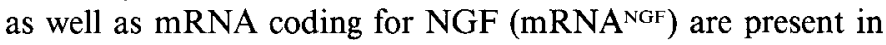
the rat brain (Korsching et al., 1985; Shelton and Reichardt, 1986; Whittemore et al., 1986; Auburger et al., 1987). Endogenous levels of NGF are highest in the hippocampus, cortex, and the basal forebrain, and $\mathrm{mRNA}{ }^{\mathrm{NGF}}$ concentrations are highest in the hippocampus and cortex. The distribution of NGF 
and mRNA ${ }^{\mathrm{NGF}}$ supports the view that NGF is synthesized by the target areas of cholinergic neurons and retrogradely transported to the cell body of responding neurons in the basal forebrain. A second group of findings demonstrates that central cholinergic neurons contain receptors for NGF. When radioactive NGF is injected into the intact hippocampus and cortex of an adult rat, it is retrogradely transported to the medial septum and nucleus basalis (Schwab et al., 1979; Seiler and Schwab, 1984). Using either radioactively labeled NGF or specific antibodies against NGF-R, these receptors have been demonstrated and visualized both in adult rat brain (Richardson et al., 1986; Taniuchi et al., 1986; Springer et al., 1987) and in human basal forebrain (Hefti et al., 1986b). In human forebrain, NGF-R were colocalized with $\mathrm{AChE}$, indicating their selective localization on cholinergic neurons (Hefti et al., 1986b). Buck et al. (1987) have recently demonstrated that mRNA for NGF-R is present in rat basal forebrain. Third, the notion that NGF is an endogenous trophic factor for basal forebrain cholinergic neurons is supported by experiments with rats with lesions of the septohippocampal pathway, which represents part of the projection system of forebrain cholinergic neurons. Intraventricular injections of NGF were found to elevate ChAT activity in septum and in hippocampus in these animals (Hefti et al., 1984) and to prevent the retrograde degeneration of cholinergic neurons in the septum (Hefti, 1986; Williams et al., 1986; Kromer, 1987).

Besides playing a role in the function of cholinergic cells in the adult brain, NGF affects their development. It has been well established that fetal basal forebrain cholinergic neurons grown in culture respond to NGF, as manifested by an increase in ChAT activity (Honegger and Lenoir, 1982; Hefti et al., 1985a; Hatanaka and Tsukui, 1986; Honegger et al., 1986; Martinez et al., 1987). Similar NGF-mediated increases in ChAT activity were observed in neonatal rats in vivo after intraventricular administration of NGF (Gnahn et al., 1983; Mobley et al., 1986). More recently, it has been demonstrated that NFG stimulates the growth of cholinergic axons from cultured septal slices to cocultured slices of hippocampal tissue (Gähwiler et al., 1987). Furthermore, measurements of NGF and mRNA ${ }^{\mathrm{NGF}}$ levels in the developing brain imply a role for NGF in the establishment of the cholinergic projection to the hippocampus. First axons from the septum reach the hippocampal formation by fetal day 20. By postnatal day 14 septal fibers have assumed the highly segregated pattern of the adult (Milner et al., 1983). The postnatal development of the cholinergic projection is reflected in the approximately 10-fold increase in ChAT activity in hippocampus. Parallel to the increase in hippocampal ChAT activity there is an identical, but slightly earlier, increase in hippocampal NGF levels. Changes in the levels of NGF in hippocampus are followed by similar changes in the basal forebrain. NGF localized in the basal forebrain is most likely retrogradely transported from hippocampus and cortex, since very little $\mathrm{mRNA}^{\mathrm{NGF}}$ is found in this region (Large et al., 1986; Whittemore et al., 1986; Auburger et al., 1987).

We have developed primary cell culture techniques to study the development of forebrain cholinergic neurons and their response to NGF. In an earlier study, pure neuronal cultures of high plating density were prepared, in which the proliferation of non-neuronal cells was suppressed by the addition of cytostatic compounds (Hefti et al., 1985a). Addition of NGF to such cultures elevated the biochemically measurable activity of ChAT approximately 2 -fold, and this effect was blocked by antibodies to NGF. However, addition of NGF or antibodics to NGF to the medium of these cultures did not affect the number of surviving cholinergic neurons. Furthermore, NGF and anti-NGF failed to influence the number of proximal processes of these neurons. These observations led us to conclude that the role of NGF in the development of forebrain cholinergic neurons is a rather limited one (Hefti et al., 1985a). We now report the results of studies on basal forebrain cholinergic neurons grown in various culture conditions. NGF was found to promote survival and fiber growth of forebrain cholinergic neurons grown in cultures of low density. Furthermore, both basal levels of ChAT and $\mathrm{AChE}$ and NGF-mediated increases in activities of these enzymes were found to be influenced by the presence of astrocytes.

Preliminary reports of this work appeared in abstract form (Hartikka and Hefti, 1985, 1986).

\section{Materials and Methods}

Preparation of cell cultures. The septal region was dissected under a stereomicroscope from fetal rats (Wistar) of embryonic age E16-E18 (Fig. 1). The localization of cholinergic cell bodies in the septal area was derived from the description of fetal rat brain anatomy (lnagaki et al., 1982) and by histochemical staining for AChE, which at E17 weakly labeled cell bodies close to the midline in the septal area. The septal region as dissected in these experiments contains cholinergic cells belonging to the group of ascending cholinergic neurons of the basal forehrain, which, in the adult brain, are localized in the medial septal nucleus and the nucleus of the diagonal band of Broca (Mesulam et al., 1983a, b; Wainer et al., 1984; Woolf et al., 1984). The septal area dissected does not contain cholinergic neurons belonging to the nucleus basalis or to the corpus striatum. A detailed description of the dissection has been published elsewhere (Hefti et al., 1987).

Dissected pieces of septal tissue were transferted into a culture dish containing dissociation medium [Minimum Essential Medium (MEM) with sodium bicarbonate, $\mathrm{pH}$ 7.4]. Meninges were carefully removed. I he septal tissue was further minced into small pieces $\left(<1 \mathrm{~mm}^{2}\right)$, which were then transferred into a sterile tube. The dissociation medium was removed by aspiration, and $1 \mathrm{ml}$ of a trypsin solution $[1 \%$ trypsin (Gibco) in PBS] and $1 \mathrm{ml}$ of a deoxyribonuclease solution [0.1\% DNAse (type 1, Sigma) in PBS] was added. Tissue pieces were then incubated during $10-15 \mathrm{~min}$ at $37^{\circ} \mathrm{C}$. The supernatant was removed after incubation, and the tissue pieces were washed twice with dissociation medium. After the final wash, $5 \mathrm{ml}$ of dissociation medium and $0.1 \mathrm{ml}$ of $0.1 \%$ DNAse solution were added to the tissue pieces. Cells were then dissociated by gentle trituration with a fire-polished Pasteur pipet. Addition of DNAse to the medium prevents the formation of sticky agglomerates which cannot be further separated. After trituration, cells were spun down in a centrifuge at $200 \times g(5-10 \mathrm{~min})$. The supernatant was discarded, and the dissociated cells were resuspended by mild trituration in 1-4 $\mathrm{ml}$ of growth medium (see below).

Cells were counted in a hemocytometer (using exclusion of trypan blue as criterion for viability) and plated in previously prepared culture dishes. For immunocytochemistry and for biochemical experiments, an aliquot yielding $0.5-0.6 \times 10^{6}$ viable cells was added to each well of 16 $\mathrm{mm}$ diameter in multiwell plates (Costar). These cultures were called "high-density cultures" (approximately 300,000 cells plated $/ \mathrm{cm}^{2}$ ). For image-analysis studies, an aliquot resulting in $0.8-1.6 \times 10^{6}$ viable cells was added to each $35 \mathrm{~mm}$ culture dish (Costar). These cultures were called "low-density cultures" (approximately 150,000 cells plated $/ \mathrm{cm}^{2}$ ).

Culture conditions. Culture dishes were coated with polyethylenimine (PEI, Sigma Chemical Co.). PEI is an artificial polycationic substrate with properties similar to those of the commonly used coating materials, polyornithine and poly(L-lysine) (Ruegg and Hefti, 1984). A solution of $1 \mathrm{mg} / \mathrm{ml}$ PEI in $0.15 \mathrm{M}$ sodium borate buffer, $\mathrm{pH} 8.3$, was applied overnight. Then the dishes were washed 3 times with sterile PBS.

Neurons were grown in a modified L- 15 medium containing $5 \%$ horse serum and $0.5 \%$ fetal bovine serum. The L-15 medium is a modification of the growth medium originally developed for sympathetic neurons (Mains and Patterson, 1973). It was prepared by adding the following chemicals to basal L-15 medium (Gibco): $10.8 \mathrm{gm} /$ liter of glucose, 1.1 $\mathrm{gm} /$ liter of glutamine, $5 \mathrm{mg} /$ liter of $\beta$-alanine, $15 \mathrm{mg} /$ liter of aspartic 


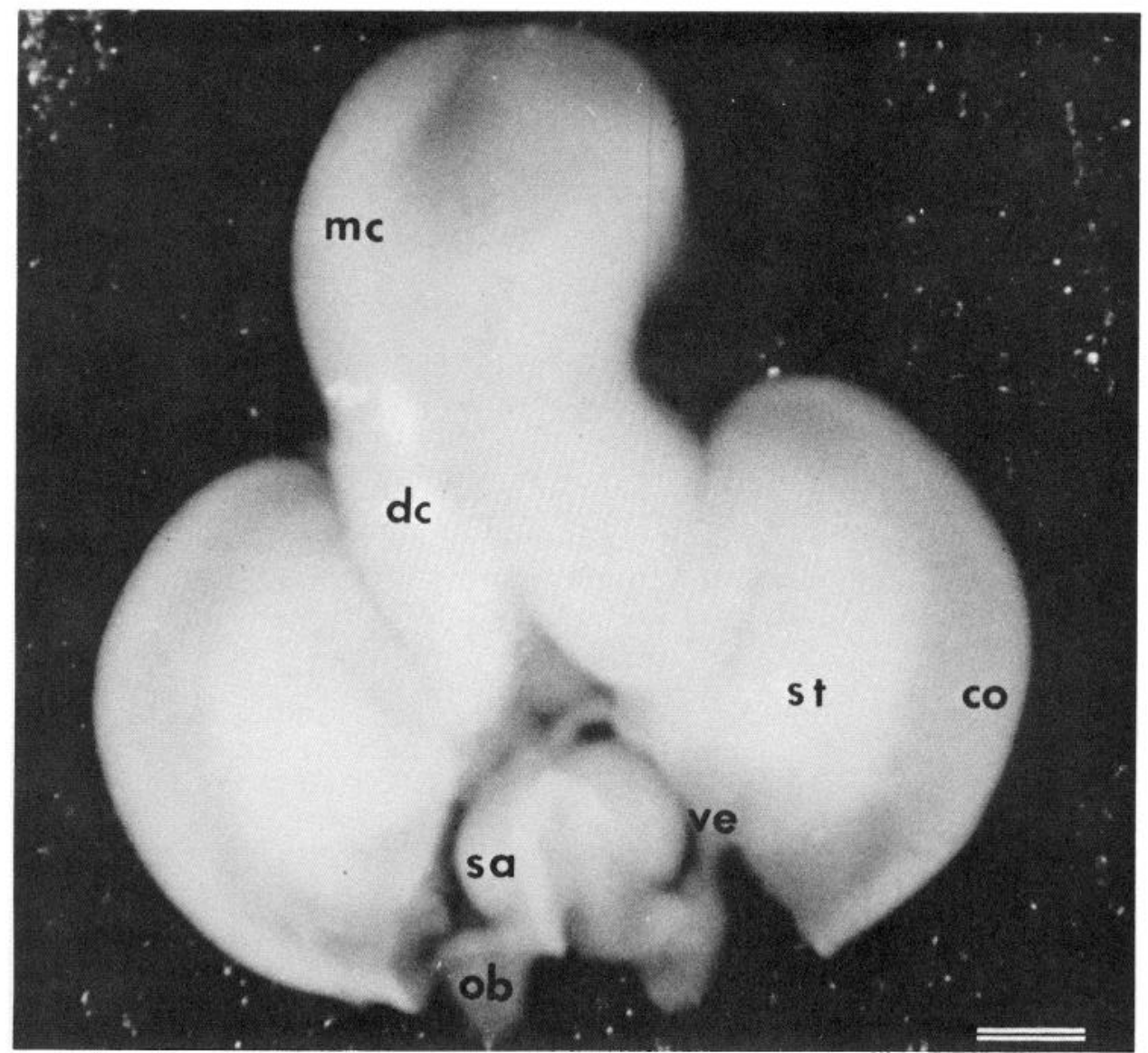

Figure 1. Dissection of septal region from fetal rat of embryonic age E17. The brain was carefully pushed out of the skull and put on its ventral surface under a stereomicroscope. The cortical hemispheres were slightly pulled away from the brain's midline. This procedure makes visible the septal area, which, at this embryonic age, has the form of 2 slightly bent cylindrical structures occupying approximately the first millimeter lateral to the midline. The septal area appears denser than the cortical tissue adjacent to it. Using a small scalpel, the septal area was dissected by making 2 vertical cuts along the first and the second ventricle, which are clearly visible between septal structures and striatum. A third vertical and transverse cut was made at the borderline separating the septal area from the diencephalon. A fourth cut was made to separate olfactory bulbs from septal area. Scale bar, $1 \mathrm{~mm}$. Abbreviations: $c o$, cortex; $d c$, diencephalon; $m c$, mesencephalon; $o b$, olfactory bulb; $s a$, septal area; st, striatum; ve, ventricle. acid, $15 \mathrm{mg} /$ liter of cystine, $15 \mathrm{mg} /$ liter of glutamic acid, $5 \mathrm{mg} /$ liter of para-aminobenzoic acid, $61 \mathrm{mg} /$ liter of ascorbic acid, $10 \mathrm{mg} / \mathrm{liter}$ of choline chloride, $25 \mathrm{mg} /$ liter of fumaric acid, $3 \mathrm{mg} /$ liter of glutathione, $60 \mathrm{mg} /$ liter of imidazole, $10 \mathrm{mg} /$ liter of myoinositol, $0.5 \mathrm{mg} /$ liter of $\alpha$ lipoic acid, $2 \mathrm{mg} /$ liter of vitamin $\mathrm{B}_{12}$, and 100,000 units/liter of penicillin-G and $100 \mathrm{mg} /$ liter of streptomycin. Eighty milliliters of this modified L-15 medium were mixed with $20 \mathrm{ml}$ of $0.15 \mathrm{M} \mathrm{NaHCO}_{3}, 5$ $\mathrm{ml}$ of horse serum, and $0.5 \mathrm{ml}$ of fetal bovine serum (Gibco). Sera were heat inactivated for $30 \mathrm{~min}$ at $56^{\circ} \mathrm{C}$. Cells were incubated at $37^{\circ} \mathrm{C}$ in a $95 \%$ air $/ 5 \% \mathrm{CO}_{2}$ humidified atmosphere. The medium was exchanged every $3-4 \mathrm{~d}$.

Cultures, where non-neuronal cells were able to proliferate freely, were called "mixed neuronal-glial cultures." To obtain cultures free of nonneuronal cells, $2-5 \mu \mathrm{M}$ of cytosine arabinonucleoside (Ara-C) was added to the medium $24 \mathrm{hr}$ after plating. Ara-C was then present in the medium during the entire culture period. Addition of Ara-C suppressed the proliferation of non-neuronal cells. Therefore, these cultures were operationally defined as "pure neuronal cultures."

ChAT immunocytochemistry. Cultures were washed 3 times with PBS, fixed for $30 \mathrm{~min}$ in $4 \%$ formaldehyde at $20^{\circ} \mathrm{C}$ and were then washed for $2-4 \mathrm{hr}$ with $0.1 \mathrm{M}$ sodium phosphate buffer, $\mathrm{pH}$. 7.4 , containing $5 \%$ sucrose, $5 \%$ bovine serum albumin, and $0.1 \%$ Triton X-100 (PS solution). Then cultures were incubated for $12 \mathrm{hr}$ at $4^{\circ} \mathrm{C}$ with PS containing a monoclonal antibody to ChAT (Eckenstein and Thoenen, 1982) and normal rabbit serum (1:100 dilution). Cultures were washed with PS and were incubated with biotinylated anti-rat antibody (1:200 in PS, Vector Laboratories, Burlingame, CA). Thereafter, they were washed in PS and PBS and incubated with an avidin-biotin conjugate of peroxidase (Vectastain). The peroxidase was visualized using diaminobenzidine and hydrogen peroxide. The cultures were then washed with PBS and embedded in glycerol gelatin. To test the specificity of the staining, monoclonal rat anti-ChAT was replaced by purified rat IgGs (Sigma).

NGF receptor immunocytochemistry. Cultures were washed 3 times with PBS, fixed for $20 \mathrm{~min}$ in $4 \%$ formaldehyde at $20^{\circ} \mathrm{C}$ and were then washed for $2-4 \mathrm{hr}$ with PS solution containing $0.02 \%$ Triton X-100.
Then cultures were incubated for $12 \mathrm{hr}$ at $4^{\circ} \mathrm{C}$ with a monoclonal antibody against NGF-R $(5 \mu \mathrm{g} / \mathrm{ml}$ of affinity-purified antibody $192-\mathrm{IgG}$ in PS solution: Chandler et al., 1984; Taniuchi and Johnson, 1985) and normal horse serum (1:100 dilution). In control dishes, antibody 192-IgG was replaced by unspecific mouse immunoglobulines (Vector Laboratories). Dishes were then stained by the successive addition of biotin-conjugated horse anti-mouse IgG ( $1: 200$, Vector Laboratories), avidin-biotin complex, and diaminobenzidine. Washes between steps were done in PBS with 5\% sucrose.

Some cultures were taken for costaining with NGF-R immunocytochemistry and $\mathrm{AChE}$ cytochemistry. In these experiments, septal cells were grown in high-density mixed neuronal-glial cultures in the presence of NGF for 2 weeks, after which they were taken for NGF-R immunocytochemistry. After treatment with diaminobenzidine and hydrogen peroxide, cultures were washed with PBS and incubated in AChE staining solution for $2 \mathrm{~d}$ at $4^{\circ} \mathrm{C}$, as described below.

$A C h E$ cytochemistry. For cytochemical visualization of $\mathrm{AChE}$, a modification of the method described by Geneser-Jensen and Blackstadt (1971) was used. Cultures were washed 3 times with PBS and fixed for $30 \mathrm{~min}$ in $4 \%$ formaldehyde $\left(\mathrm{pH} \mathrm{7.4)}\right.$ at $20^{\circ} \mathrm{C}$. They then were incubated for $2-4 \mathrm{~d}$ at $4^{\circ} \mathrm{C}$ in $50 \mathrm{~mm}$ acetate buffer, $\mathrm{pH} 5.0$, containing $4 \mathrm{~mm}$ acetylthiocholine iodide, $2 \mathrm{~mm}$ copper sulfate, $10 \mathrm{~mm}$ glycine, and 10 $\mathrm{mg} / \mathrm{ml}$ of gelatin. Inclusion of gelatin prevented diffusion of the reaction product. Nonspecific cholinesterases were inhibited by inclusion of 0.2 mм of ethopropazine in the incubation medium. After the incubation, gelatin was dissolved by incubating the cultures briefly at $37^{\circ} \mathrm{C}$. They then were rinsed with distilled water, exposed for $1 \mathrm{~min}$ to $1.25 \% \mathrm{Na}_{2} \mathrm{~S}$, washed with distilled water, and exposed for $1 \mathrm{~min}$ to $1 \% \mathrm{AgNO}_{3}$. The cultures were then washed with water and embedded in glycerol gelatin. Specificity of the staining was tested using the AChE inhibitor, 1,5-bis(4-allyldimethyl-ammonium-phenyl)-pentan-3-one dibromide (BW 248C51).

Glial fibrillary acid protein immunocytochemistry. Glial fibrillary acid protein (GFAP) was visualized immunocytochemically according to the method of Manthorpe et al. (1979). Cultures were fixed with a mixture 
of 3 parts of acetone and 2 parts of ethanol. They then were incubated for $12 \mathrm{hr}$ at $4^{\circ} \mathrm{C}$ with PS containing 1:500 dilution of rabbit antiserum to human GFAP (Dakopatts) and normal goat serum (1:100). Dishes were then staincd by the successive addition of biotin-conjugated goat anti-rabbit IgG (1:200 dilution, Vector Laboratories), avidin-biotin complex, and diaminobenzidine. Washes between steps were done with PBS.

Quantification of cell number. The total number of neurons or the number of stained cells per dish was established by counting them in randomly distributed visual fields using either a Leitz Labovert or Leitz Dialux 22 microscope. The number of stained cells was counted in several visual fields corresponding to $5-20 \%$ of the total area of the culture dish. The mean number of cells counted in each of 10-25 representative fields was multiplied by the number of visual fields per dish to provide an estimate of the total number of cells.

Image analysis. Low-density septal cultures were grown for 14-21 d. Thereafter, they were stained for $\mathrm{AChE}$ and taken for morphometric analysis. Morphological characteristics of individual cholincrgic ncurons were analyzed using a computerized image-analysis system. The system consisted of a Leitz Dialux 22 microscope fitted with a Dage 66 SIT video camera, a Panasonic WV-5410 video monitor, a Houston Hi-Pad graphics tablet, a Compaq microcomputer, and the Micro-Comp Data Acquisition System (Southern Micro Instruments, Atlanta, GA). This image-analysis system permitted the user to trace neuronal processes on the video monitor via interaction with the graphics tablet. The following parameters were measured from each cholinergic neuron: total length of fibers of an individual cell, total number of branching points, and average distance between 2 branching points.

Determination of ChAT and AChE activity. Cultures were washed 3 times with PBS and homogenized by sonication in $250 \mu \mathrm{l}$ of a $50 \mathrm{~mm}$ Tris- $\mathrm{HCl}$ buffer, $\mathrm{pH} 6.0$, containing $0.3 \%$ Triton X-100. Aliquots (30 $\mu$ ) of the homogenate werc taken for the determination of ChAT activity according to the method of Fonnum $(1975) \cdot 1-{ }^{14} \mathrm{C}$-acetyl-coenzyme $\mathrm{A}$ (Amersham CFA.452) was diluted with unlabeled acetyl-CoA to give a final substrate concentration of $20 \mu \mathrm{M}$ (specific activity, $4.09 \mathrm{Ci} / \mathrm{mol}$ of acetyl-CoA). Specificity of the enzyme determination was assessed by using the ChAT inhibitor $N$-hydroxyethyl-4-(1-naphthyl-vinyl)pyridium bromide (Calbiochem). Aliquots $(20 \mu$ l) of the homogenate were taken for the determination of $\mathrm{AChE}$ activity according to the method of Potter (1967), with the modifications described by Johnson and Russell (1975). ${ }^{3} \mathrm{H}$-Acetylcholine chloride (Amersham TRA.277) was diluted with unlabeled acetylcholine chloride to give a final substrate concentration of $2.0 \mathrm{~mm}$ (specific activity, $0.42 \mathrm{Ci} / \mathrm{mol}$ of acetylcholine chloride). Specificity of the enzyme determination was assessed by using the AChE inhibitors diisopropyl-fluorophosphate (DFP, $10 \mu \mathrm{M}$ ), physostigmine $(10 \mu \mathrm{M})$ or 1,5-bis-(4-allyldimethyl-ammonium-phenyl)-pentan-3-one dibromide (BW 248C51, $1 \mu \mathrm{M}$ ). Specific enzyme activities were based on the protein content of the cultures, which was measured according to the method of Bradford (1976) using bovine gamma-globulin (Bio-Rad) as a standard.

Materials. Chemicals of analytical grade were purchased from Sigma, if not otherwise stated. Media and sera for tissue cultures were obtained from Gibco. Mouse NGF was purified from adult mouse submandibular glands according to the method of Bocchini and Angeletti (1969), with the modifications described by Suda et al. (1978). A polyclonal sheep anti-NGF serum (Suda et al., 1978) was used, $1 \mu$ l of which inhibited the biological activity of $2 \mu \mathrm{g}$ of NGF. Affinity-purified monoclonal antibody $192-\mathrm{IgG}$ against rat NGF receptor was a gift from Dr. E. M. Johnson (Washington University School of Medicine, St. Louis, MO). The RS/ 1 data analysis system (BBN Software Products, Cambridge, MA) was used for statistical analysis of the data.

\section{Results}

Cultures

We chose 16- to 18-d-old fetuses as the source of brain tissue because, at this stage, most neurons in the septal rcgion just completed their final division and because there are relatively few glial precursors present at this time (Bayer, 1979). During the past 5 years culture conditions were optimized for septal neurons to produce maximal growth and marker enzyme activities. The modified L-15 growth medium proved to be superior to other tested media (i.e., Dulbecco's modified Eagle's medium, Eagle's MEM, F-12 medium, McCoy's 5A medium, Medium
199, and RPMI-1640) in supporting survival and ChAT activity of septal cultures. Gentle enzymatic and mechanical dissociation of brain tissue from rat fetuses yielded a high proportion of viable cells. Over $90 \%$ of the cells dissociated from the septal region excluded trypan blue, a high-molecular-weight dye for viability test. The average total number of dissociated septal cells obtained from E16, E17, and E18 fetuses was $0.58 \times 10^{6}$, $0.81 \times 10^{6}$, and $1.16 \times 10^{6}$ cells per fetus, respectively. Many of the dissociated cells retained short fibers and had recognizable neuronal morphology. Cells rapidly adhered to PEI-coated culture dishes and began to extend processes within a few hours. At the time of plating, most of the cells appeared to be neurons, which were identified as phase-bright cells with surrounding halos and thin processes. There were very few non-neuronal cells present (Fig. 2A).

During the subsequent days in culture, neuronal processes increased in length and number. In mixed neuronal-glial cultures, non-neuronal cells started to multiply rapidly after $3-4 \mathrm{~d}$ in vitro (Fig. $2 B$ ). By the end of the first week, non-neuronal cells formed a confluent background layer in cultures of high plating density (Fig. 2C). Almost all of the flat cells or processbearing cells with processes of variable diameter contained GFAP and were thus identified as astrocytes (Fig. 2E). Oligodendrocytes (identified by immunocytochemical staining of myelin basic protein) and fibroblasts (identified with fibronectin immunocytochemistry) were not present in significant numbers. Immunocytochemical staining of neurofilaments revealed that nearly all of the cells having neuronal morphology and thin processes contained neurofilaments (data not shown). Ten days after plating, mixed cultures contained approximately an equal number of neurons and astrocytes. After more than 2 weeks in vitro, the number of astrocytes exceeded that of neurons because non-neuronal cells continued to proliferate, whereas the number of surviving neurons decreased gradually. However, many cholinergic neurons could still be visualized with AChE cytochemistry in 1 -month-old mixed neuronal-glial cultures.

Pure neuronal cultures were obtained only if the initial plating density was high. After $10 \mathrm{~d}$ in vitro, neurons in such cultures had grown a monolayer and formed an extensive network of processes (Fig. $2 D$ ). Lcss than $5 \%$ of all cells in pure ncuronal cultures were identified as astrocytes. Most of the remaining astrocytes were smaller than those observed in mixed neuronalglial cultures (Fig. $2 F$ ). The number of neurons in these cultures remained virtually constant from day 3 to day 14 after plating. Thereafter, the number of neurons declined rapidly, resulting in complete degeneration of pure neuronal cultures 3 weeks after plating.

Initial survival of cells was the same in high- and low-density cultures. The majority $(>75 \%)$ of plated cells were viable after $1 \mathrm{~d}$ in culture as assessed by counting the number of processbearing cells using phase-contrast microscopy. Thereafter, survival of neurons was dependent on the plating density. In 3-dold cultures, approximately $57 \%\left(170,000\right.$ cells $\left./ \mathrm{cm}^{2}\right)$ and $23 \%$ $\left(35,000\right.$ cells $\left./ \mathrm{cm}^{2}\right)$ of plated cells were growing in high- and lowdensity cultures, respectively (Fig. 3). Neurons in low-density cultures could be kept alive for more than $3 \mathrm{~d}$ only if proliferation of glial cells was not inhibited. However, glial proliferation in these cultures was slow. It took nearly 2 weeks for astrocytes to form a confluent cell layer in low-density cultures. Differences in initial plating density and in cell survival resulted, therefore, into 2 very distinct types of cultures: high-density mixed cultures, in which neurons were densely packed and where glial proliferation was rapid, and low-density mixed cultures, in 

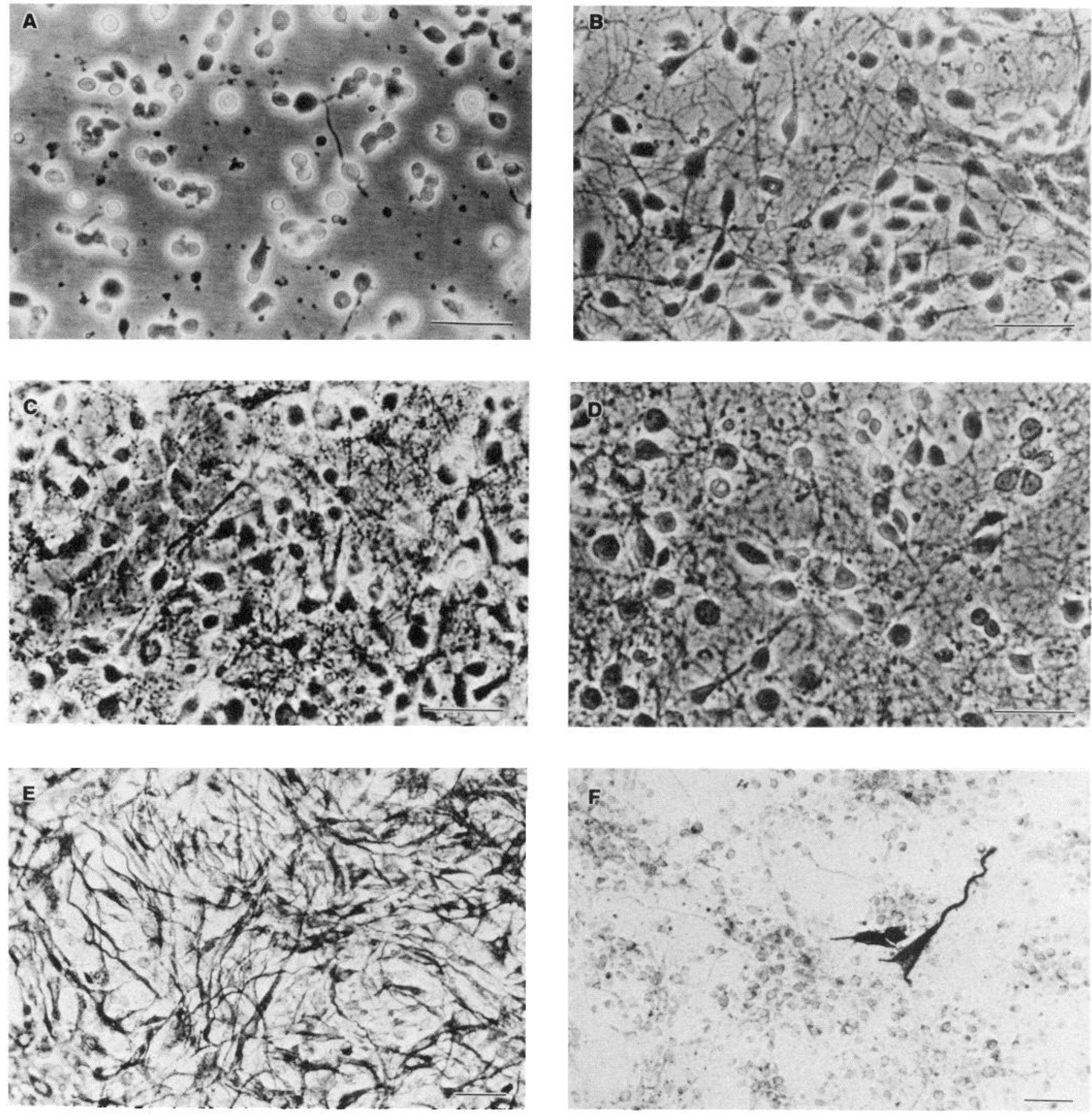

Figure 2. Mixed neuronal-glial cultures and pure neuronal cultures. Phase-contrast micrographs $(A-D)$ and GFAP immunocytochemistry $(E, F)$ of dissociated cultured neurons from fetal rat septum. Representative fields from high-density cultures were photographed under phase-contrast optics $2 \mathrm{hr}(A), 3 \mathrm{~d}(B)$, and $10 \mathrm{~d}(C, D)$ after plating. In 10-d-old mixed neuronal-glial cultures $(C, E)$, neurons were surrounded by a confluent background layer of glial cells. Approximately $50 \%$ of all cells in these cultures were astrocytes, as identified by immunocytochemical visualization of glial fibrillary acid protein $(E)$. In 10-d-old pure neuronal cultures $(D, F)$, neurons formed a monolayer, and there was an extensive network of neuronal processes. Less than $5 \%$ of all cells in these cultures were astrocytes, as identified by GFAP immunocytochemistry $(F)$. Note difference in magnification between $A-D$ and $E / F$. Scale bars, $40 \mu \mathrm{m}$.

which neurons grew apart from each other and where glial cells proliferated slowly.

\section{$N G F$ increases staining intensity in ChAT and NGF- $R$ immunocytochemistry}

Cholinergic neurons were identified by ChAT immunocytochemistry and AChE cytochemistry. ChAT immunocytochem- istry stained cell bodies and proximal processes, while AChE cytochemistry visualized the entire neuron. Earlier studies showed that $\mathrm{AChE}$ is a reliable marker for cholinergic neurons in the basal forebrain. We demonstrated that all of the ChATpositive neurons in cultures prepared from fetal rat septum were costained for AChE, while only $6 \%$ of the AChE-positive cells were ChAT-negative (Hefti et al., 1985a). Also in vivo, there is 


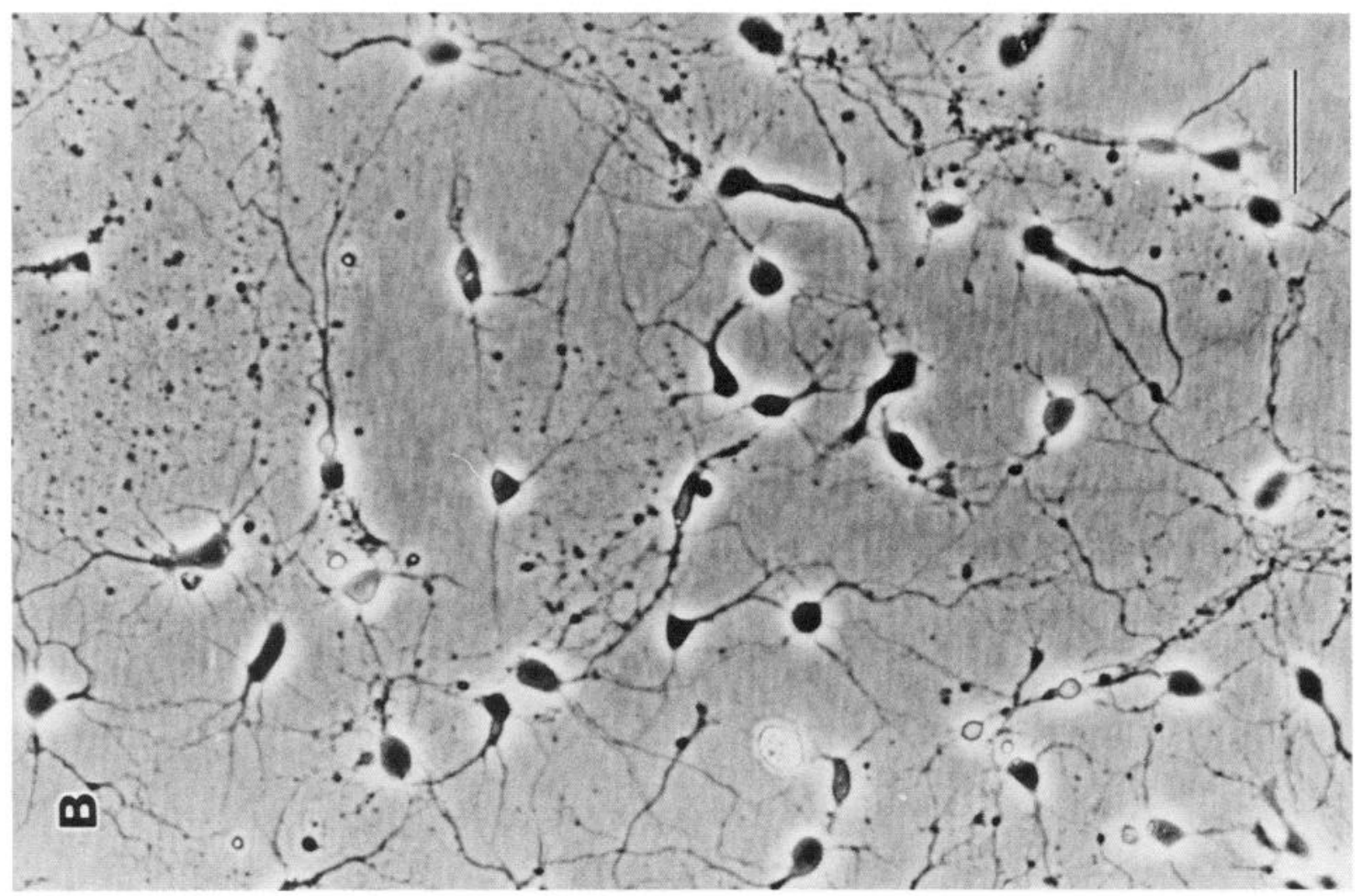

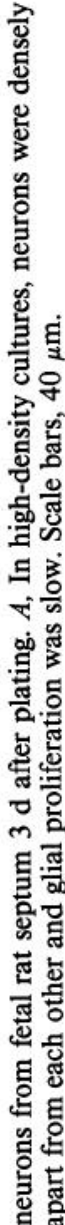

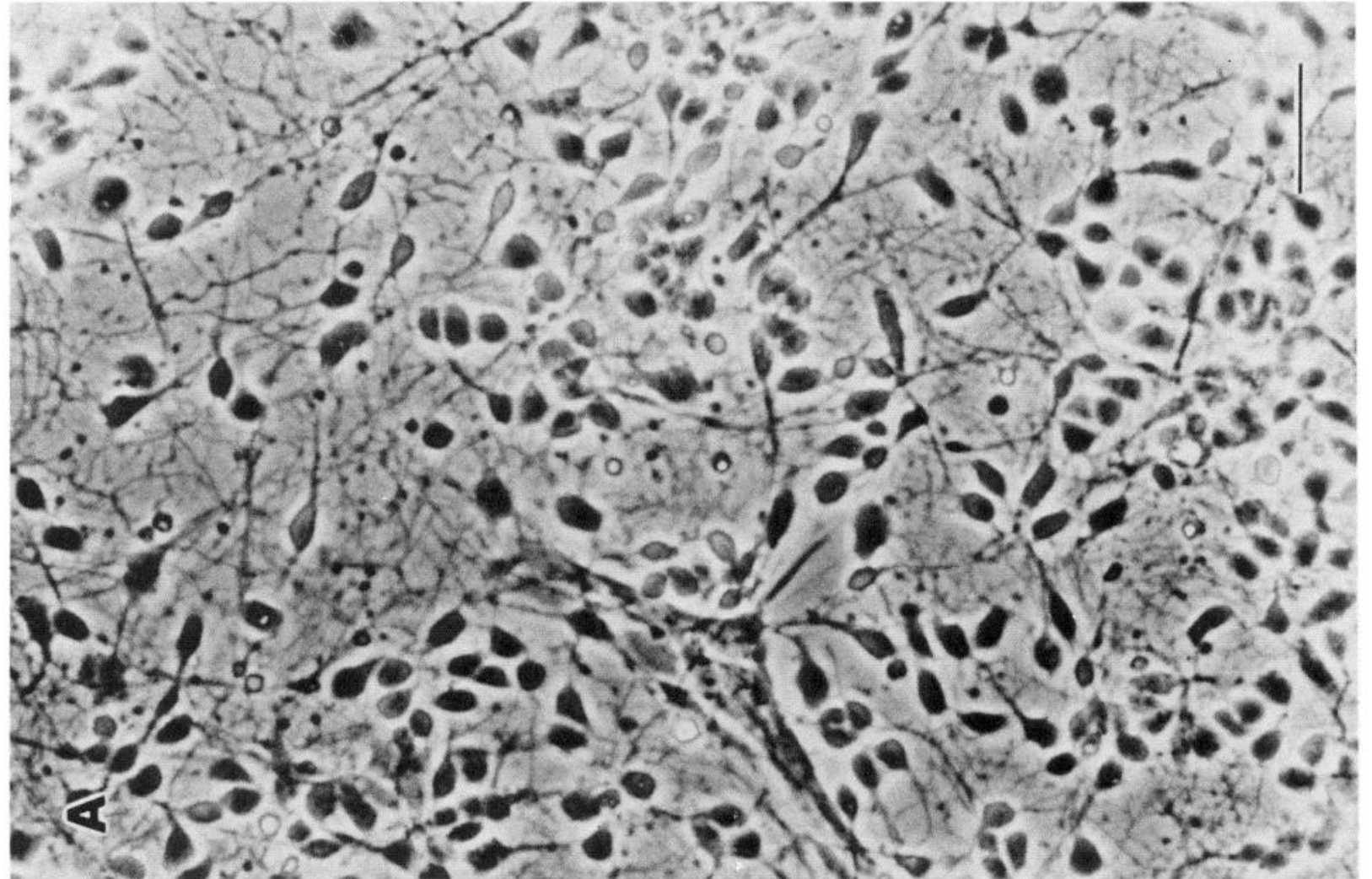



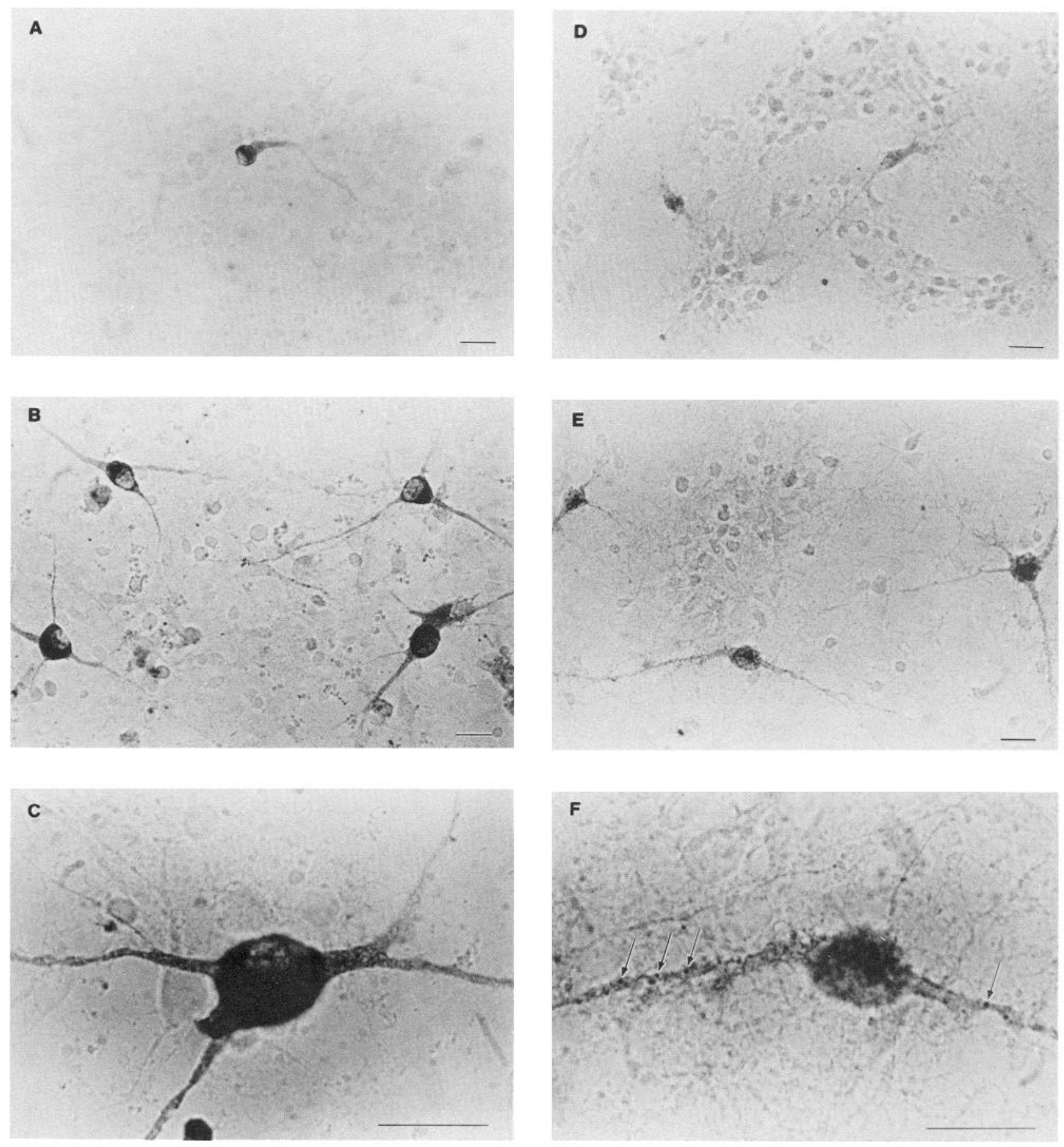

Figure 4. ChAT and NGF-R immunocytochemistry in 2-week-old septal cultures. Septal cells were grown at high density in mixed neuronalglial cultures. ChAT immunocytochemistry $(A-C)$ and NGF-R immunocytochemistry $(D-F)$ stained cell bodies and proximal processes. In control cultures, both ChAT staining $(A)$ and NGF-R staining $(D)$ was relatively weak. Treatment of cultures with NGF $(100 \mathrm{ng} / \mathrm{ml})$ increased the staining intensity of both ChAT $(B, C)$ and NGF-R immunocytochemistry $(E, F)$. The reaction product of ChAT staining was evenly distributed in the cytosplasm $(C)$. Occasionally, NGF-R staining $(F)$ was concentrated in the perinuclear area of the cell body and on the surface of the cell membrane (arrows). Scale bars, $20 \mu \mathrm{m}$.

a good correlation between these 2 enzymes in the basal forebrain. In monkey and rodent brain, $80-88 \%$ of all AChE-positive neurons in the medial septum, diagonal band, and nucleus basalis of Meynert were costained for ChAT (Eckenstein and Sofroniew, 1983; Levey et al., 1983; Mesulam et al., 1984).

Cholinergic neurons constituted approximately $1 \%$ of all neurons in high-density cultures. The actual value varied from ex- periment to experiment and ranged from 0.2 to maximally $5 \%$. ChAT-positive cell bodies had a diameter of $15-25 \mu \mathrm{m}$, and they were larger than average neurons (Fig. $4 A-C$ ). The reaction product in ChAT immunocytochemistry was evenly distributed in the cytoplasm and in the proximal processes (Fig. $4 C$ ). NGF treatment increased both the number of ChAT-positive cells per dish and the staining intensity of individual cholinergic neurons. 
In control cultures, only a minor number of weakly stained neurons were visible (Fig. $4 A$ ). However, when cultures were grown in the presence of NGF, 2-3 times as many darkly stained neurons were found. NGF treatment also appeared to increase the diameter of ChAT-positive neurons (Fig. 4, $B$ and $C$ ).

To further characterize the cells that respond to $\mathrm{NGF}$ in our septal cultures, NGF-R were visualized using a monoclonal antibody 192-IgG. This antibody recognizes NGF receptors of rat PC12 cells (Chandler et al., 1984) and was extensively characterized on rat sensory neurons (Taniuchi and Johnson, 1985) and in the rat brain (Taniuchi et al., 1986). The antibody labeled a minority of neurons in our cultures. The number and morphology of these cells were similar to those of neurons stained with ChAT immunocytochemistry. Receptors for NGF were located in the cell body and on the outer membrane of proximal processes (Fig. $4 D-F$ ). Occasionally, NGF-R were concentrated in the perinuclear area of the cell body (Fig. $4 F$ ). As in ChAT immunocytochemistry, NGF treatment approximately doubled the number of NGF-R positive cells in septal cultures. In untreated cultures, only marginally stained neurons were visible $\left[591 \pm 68\right.$ NGF-R-positive cells $/ \mathrm{cm}^{2}$ (mean $\left.\pm \mathrm{SEM}\right) ; n=4$; Fig. $4 D$ ]. In NGF-treated cultures, however, a large number of darkly stained neurons was found (1052 \pm 95 NGF-R-positive cells/cm $\mathrm{cm}^{2} ; n=4$; Fig. 4, $E$ and $F$ ). Besides visualizing NGF-R on neurons, we occasionally observed receptors for NGF on flat non-neuronal cells. Based on morphological criteria, these spindle-shaped cells did not appear to be astrocytes.

\section{$N G F-R$ are localized in cholinergic neurons in septal cultures}

We earlier found that NGF increases ChAT activity in pure neuronal cultures prepared from fetal rat septum (Hefti et al., 1985a). These experiments demonstrated that the presence of glial cells is not required for NGF-mediated increase in ChAT activity and suggested, therefore, that neurons have receptors for NGF. The finding that ChAT and NGF-R immunocylochemistry visualized the same number of neurons in our cultures suggested that these receptors are located on cholinergic neurons. To test this hypothesis, cultures were taken for costaining with NGF-R immunocytochemistry and AChE cytochemistry, as described in Materials and Methods. Costaining for NGF-R and $\mathrm{AChE}$ was assessed by comparing photographs taken from the same visual fields (Fig. 5). A total of 55 visual fields was analyzed in 2 separate experiments. All of the 146 NGF-Rpositive cells were also positively stained for $\mathrm{AChE}$, indicating that NGF-R are exclusively located in cholinergic neurons in our septal cultures. Thirty-eight of the $184 \mathrm{AChE}$-positive neurons (i.e., $21 \%$ of the total) were not labeled for NGF-R. These findings are in line with those obtained from studies in vivo, showing that receptors for NGF are colocalized with cholinergic markers in rat and in human brain sections (Hefti et al., 1986b; Springer et al., 1987), and suggest that NGF affects directly and specifically only cholinergic neurons in the mammalian basal forebrain

\section{NGF increases survival of cholinergic neurons in low-density, but not high-density, cultures}

Results from ChAT and NGF-R immunocytochemistry showing that NGF treatment doubles the number of stained cells suggested that NGF increases the survival of cholinergic neurons in culture. However, these results did not provide conclusive evidence for increased survival since an elevated number of
ChAT- and NGF-R-positive cells in NGF-treated cultures might simply reflect the fact that NGF elevates the concentration of these proteins within cholinergic neurons to levels sufficiently high to permit their visualization with immunocytochemical methods. This notion was supported by our experiments showing that, when ChAT or NGF-R immunocytochemistry was followed by AChE cytochemistry, NGF did not affect the number of AChE-positive neurons in high-density cultures. In further experiments addressing the question of whether NGF or anti-NGF affects the survival of cholinergic neurons, we therefore used AChE cytochemistry, which is a reliable and more sensitive marker for cholinergic neurons in septal cultures.

We earlier reported that NGF and anti-NGF have no effect on survival of cholinergic neurons in cell cultures prepared from ral fetuses (Hefti et al., 1985a). Pure neuronal cultures of high plating density were used in these experiments. These results obtained in vitro were in apparent contradiction to our findings in vivo, showing that NGF prevents retrograde degeneration of adult septal cbolinergic neurons after fimbrial lesion (Hefti, 1986). We therefore hypothesized that either the presence of glial cells or axonal injury was required for NGF to effect survival. These hypotheses were tested with experiments on cell cultures. Two types of high-density cultures were prepared from fetal rat septum: pure neuronal cultures and mixed cultures in which neurons grew together with astrocytes. Counting of AChE-positive cells after $10 \mathrm{~d}$ in vitro showed that NGF or anti-NGF did not affect the number of cholinergic neurons either in pure neuronal cultures or in mixed neuronal-glial cultures of high plating density (Table 1), suggesting that the presence of astrocytes did not affect NGF's ability to influence survival of cholinergic neurons in high-density cultures. Based on the number of AChE-positive neurons in these cultures, we calculated that $3460 \pm 245$ (mean \pm SEM, $n=11$ ) cholinergic neurons were obtained from an E17 fetal rat septum.

To test the hypothesis that NGF promotes survival of cholinergic neurons after axonal injury only, cholinergic neurons were dissociated from the septal area of postnatal animals (P0P2), i.e., from a developmental stage, when the septal cholinergic neurons had already started to invade hippocampal tissue (Milner et al., 1983). Neurons taken for culture from such animals lost their processes during the dissociation procedure, and they were therefore comparable to neurons submitted to axonal transection in vivo. NGF significantly elevated the number of $\mathrm{AChE}-$ positive neurons surviving in these cultures, and antiserum against NGF decreased the survival of these neurons (Table 1) in apparent confirmation of our hypothesis. However, the general survival of neurons from postnatal tissue was very poor (5$20 \mathrm{AChE}$-positive cells per newborn rat), raising the possibility that NGF affected only a small subpopulation of septal cholinergic neurons. Furthermore, the high rate of neuronal death resulted in cultures of very low density, suggesting that NGF might promote the survival of cholinergic cells when these neurons are grown at low density. Further experiments were therefore done using low-density cultures prepared from E17 fetal rat septum. Addition of NGF to the medium increased the number of AChE-positive cells in low-density cultures by $78 \%$ as compared with control cultures (Table 1). The ED ${ }_{50}$ of NGF's effect on survival of cholinergic neurons was found to be approximately $10 \mathrm{ng} / \mathrm{ml}$ (corresponding to $0.4 \mathrm{nM}$ ). The stimulatory effect of NGF was prevented by the addition of antiserum to NGF, indicating that the effect was specific to NGF. Cultures grown in presence of anti-NGF alone contained significantly 

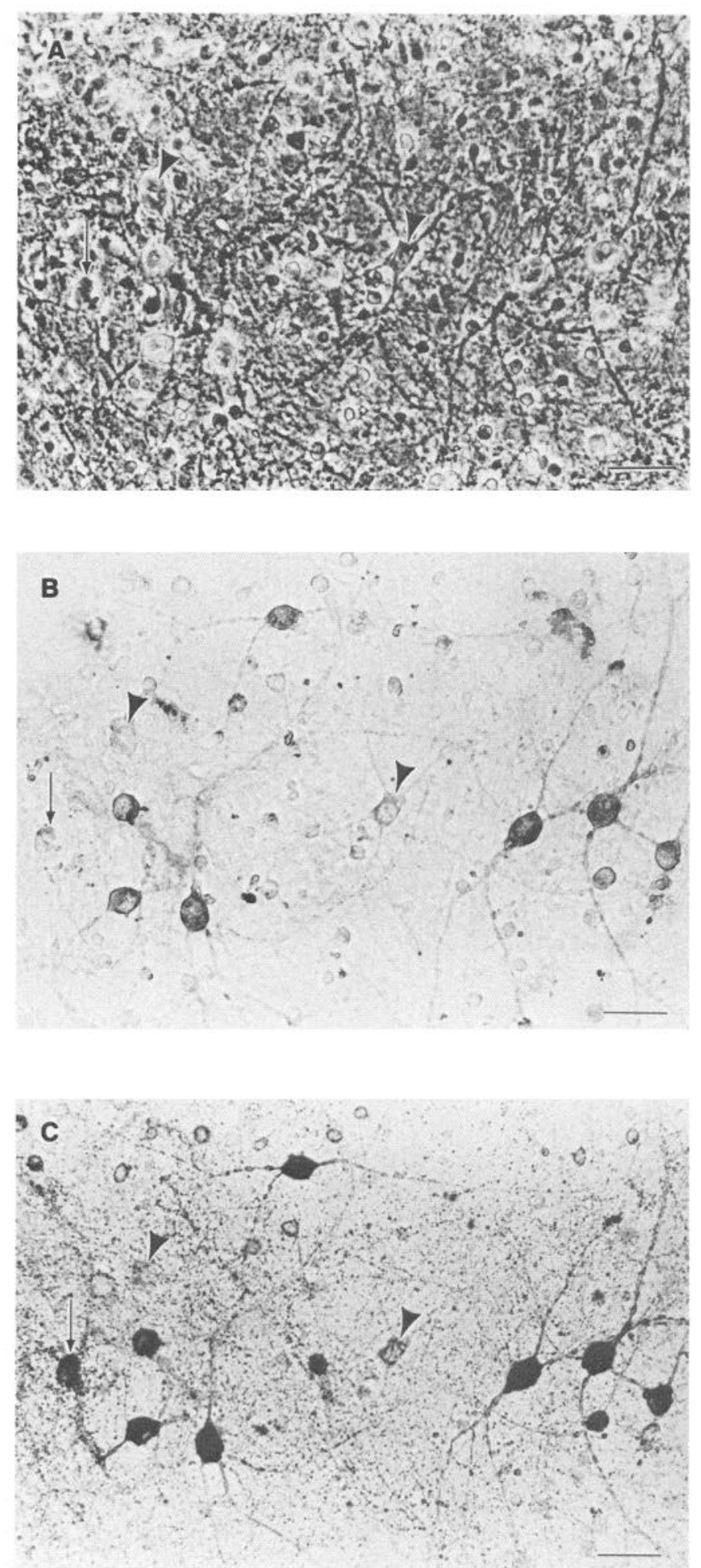
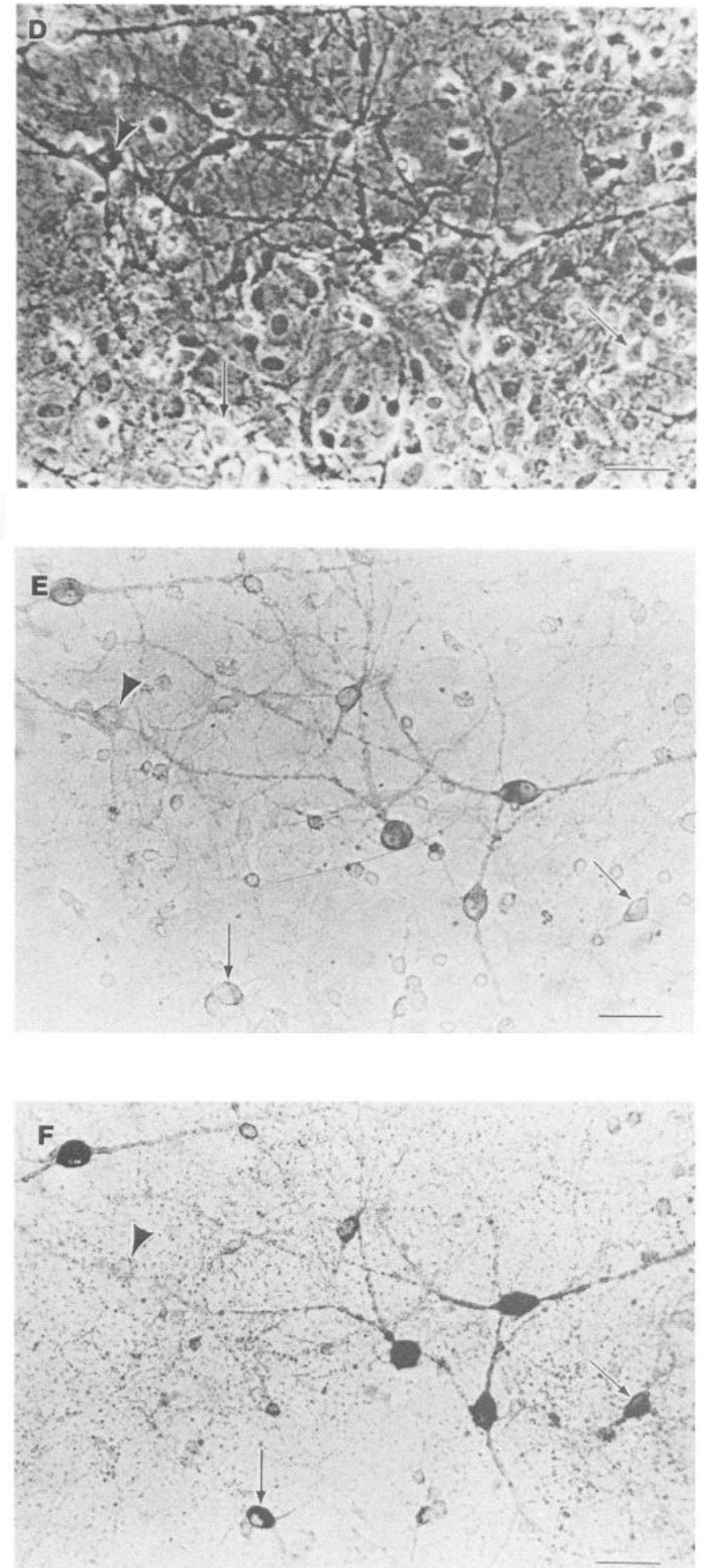

Figure 5. Double staining for NGF-R and AChE in septal cultures. High-density mixed neuronal-glial cultures were grown for 2 weeks in the presence of NGF $(100 \mathrm{ng} / \mathrm{ml})$. Thereafter, cultures were fixed and taken for NGF-R immunocytochemistry, followed by AChE cytochemistry. The same visual fields were photographed in phase-contrast $(A, D)$ and in bright field after NGF-R staining $(B, E)$ and after AChE staining $(C, F)$. A total of 55 visual fields was photographed. All NGF-R-positive cells were also positively stained for AChE. Twenty-one percent of the 184 AChEpositive neurons were not labeled for NGF-R (arrows). NGF-R and AChE-positive neurons were usually larger than average neurons (diameter of cell body, 15-25 $\mu \mathrm{m}$ ). However, there were several large neuron-type cells that were negative both in NGF-R immunocytochemistry and in AChE cytochemistry (arrowheads). Scale bars, $40 \mu \mathrm{m}$. 

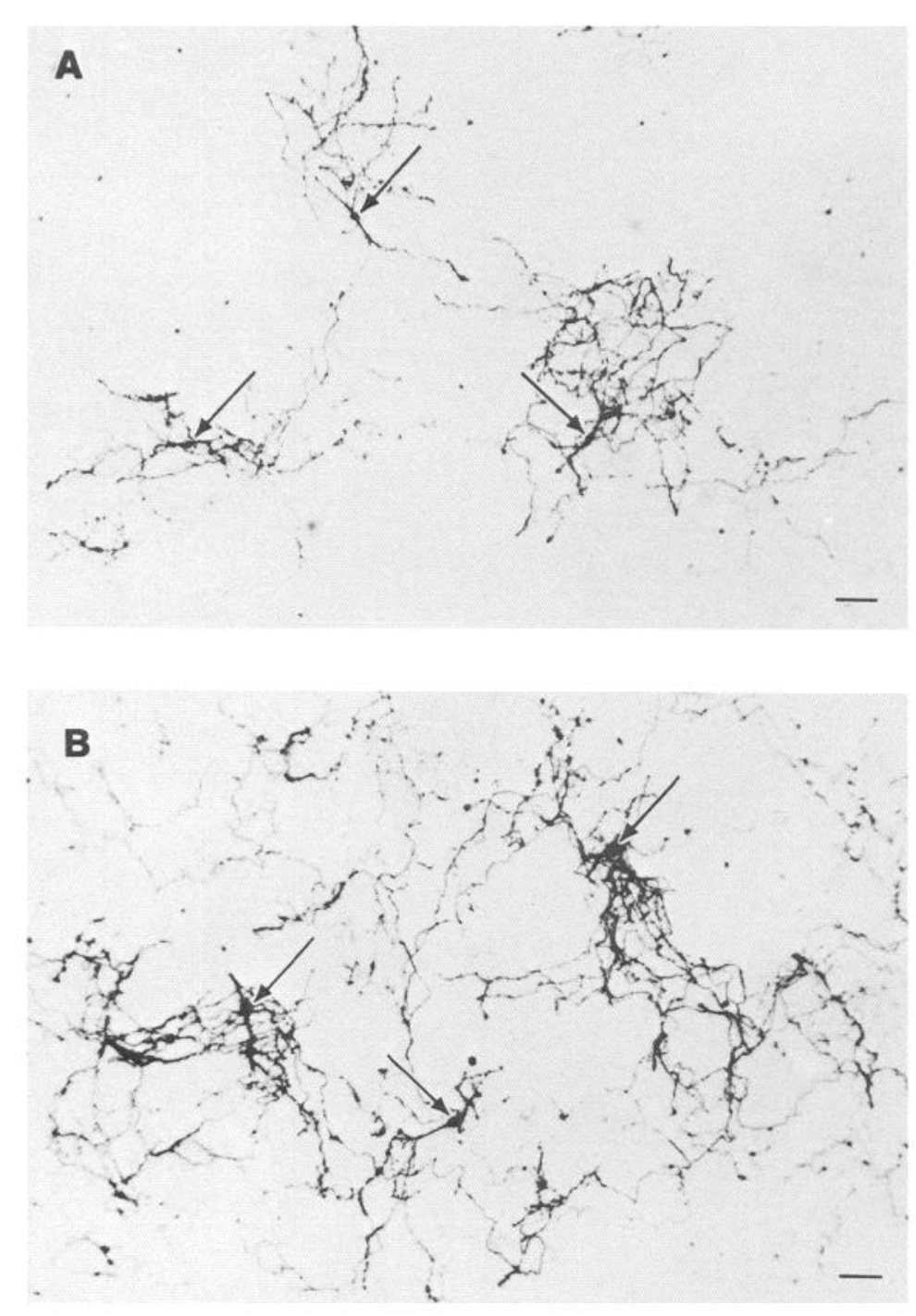

Figure 6. Stimulation of fiber growth of cholinergic neurons by NGF. Dissociated septal neurons from rat fetuses (E17) were plated at low density and grown together with glial cells. Cultures were treated either with NGF (100 ng/ $\mathrm{ml}$ ) or with a sheep antiserum against NGF (1:500 dilution). After 2-3 weeks in vitro, cholinergic neurons were visualized using AChE cytochemistry. NGF $(B)$ increased and anti-NGF $(C)$ decreased the fiber growth of cholinergic neurons compared with untreated control cultures $(A)$. Arrows point to the cell bodies of AChE-positive neurons. Scale bars, $100 \mu \mathrm{m}$.

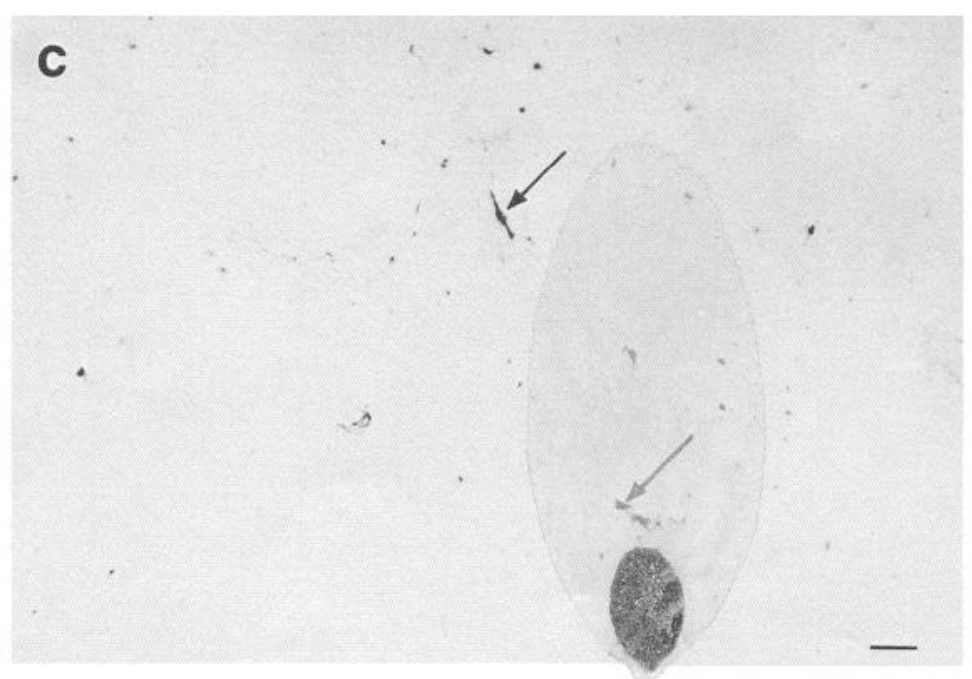

fewer AChE-positive cells than control cultures ( $54 \%$ of control value; Table 1).

The finding that NGF treatment increased and anti-NGF decreased the number of AChE-positive cells in low-density cultures might simply indicate that NGF upregulates, and antiNGF downregulates, the synthesis of AChE in low-density cultures, resulting in differences in the number of cells that are visible in AChE cytochemistry. To exclude this possibility, con- 
Table 1. Effect of NGF and anti-NGF on survival of forebrain cholinergic neurons

\begin{tabular}{|c|c|c|c|c|}
\hline \multirow[b]{3}{*}{ Group } & \multicolumn{4}{|c|}{ Number of AChE-positive neurons $/ \mathrm{cm}^{2}$} \\
\hline & \multicolumn{2}{|c|}{ Low-density cultures } & \multicolumn{2}{|c|}{ High-density cultures } \\
\hline & $\begin{array}{l}\text { Cells from } \\
\text { newborn rats }\end{array}$ & $\begin{array}{l}\text { Cells from } \\
\text { fetal (E17) rats }\end{array}$ & $\begin{array}{l}\text { Mixed } \\
\text { neuronal-glial } \\
\text { cultures }\end{array}$ & $\begin{array}{l}\text { Pure } \\
\text { neuronal } \\
\text { cultures }\end{array}$ \\
\hline Control & $2.6 \pm 0.1$ & $192 \pm 29$ & $1492 \pm 105$ & $1662 \pm 108$ \\
\hline NGF & $4.6 \pm 0.3^{a}$ & $342 \pm 58^{n}$ & $1595 \pm 135$ & $1685 \pm 112$ \\
\hline Anti-NGF & $1.1 \pm 0.2^{a}$ & $104 \pm 31^{a}$ & $1502 \pm 98$ & $1635 \pm 103$ \\
\hline
\end{tabular}

Dissociated neurons of the septal area were grown in modified L-15 medium. Low-density cultures were prepared either from newborn rats (P0-P2) or from rat fetuses (E17). Proliferation of glial cells in these cultures resulted in mixed neuronal-glial cultures. High-density cultures were prepared from fetal rat septum. Neurons in high-density cultures were grown cither together with glial cells or in pure neuronal cultures, which werc obtaincd by adding cytosine arabinoside $(2-5 \mu \mathrm{M})$ to the culture medium. Cultures were treated either with NGF $(100 \mathrm{ng} / \mathrm{ml})$ or with a sheep antiserum against NGF (1:500 dilution). After 10-14 d in vitro, the number of cholinergic neurons was counted using AChE cytochemistry. Means \pm SEM are given $(n=5-10)$.

"Significantly different from control value $(p<0.01, t$ test $)$.

trol cultures grown without NGF were treated with NGF for 2$3 \mathrm{~d}$ before fixation and staining for AChE. Short NGF treatment increased the staining intensity of cholinergic cell bodies in control cultures but did not increase the number of AChE-positive neurons. Similarly, replacing of antiserum with NGF in antiNGF-treated cultures, 2-3 d before AChE cytochemistry, did not increase the number of $\mathrm{AChE}$-positive neurons above the level observed in cultures treated with anti-NGF during the whole culture period. These results suggest that NGF and antiNGF affect survival of septal cholinergic neurons in low-density cultures but not in high-density cultures. The finding that antiNGF lowers the number of AChE-positive cells in low-density cultures suggests that NGF or other growth factors are formed by neurons and/or glial cells growing in the cultures, in sufficient quantities to support the survival of an intermediate number of cholinergic neurons.

\section{NGF increases fiber growth of cholinergic neurons}

In low-density cultures treated with NGF, AChE-positive neurons had a more extensive fiber network than in control cultures (Fig. 6). To quantify the NGF-mediated increase in fiber growth, fetal septal cells were grown in cultures of very low plating density to avoid overlapping of fibers from 2 separate cholinergic neurons. After 14-21 d in vitro, cultures were fixed, stained for $\mathrm{AChE}$, and taken for morphometric analysis of AChE-positive neurons using a computerized image-analysis system. The total length of fiber of a single cell, the total number of branching points, and the average length between 2 branching points were measured. NGF treatment increased these parameters by $30-$ $68 \%$ (Table 2). Adding antiserum against NGF in the culture medium almost completely inhibited fiber growth of cholinergic neurons (Fig. 6). AChE staining in these cultures was weak and fibers were poorly defined, precluding morphometric analysis.

\section{Astrocytes potentiate the NGF-mediated increases in ChAT and AChE activity of cholinergic neurons}

We earlier reported that NGF increases ChAT and AChE activity of cholinergic neurons in pure neuronal cultures (Hefti et al., 1985a). We now studied the effects of NGF on the expression of these enzymes in mixed cultures containing astrocytes. Highdensity cultures were used in these studies to preclude any effects of NGF on survival of cholinergic neurons (Table 1). When NGF $(100 \mathrm{ng} / \mathrm{ml})$ was added to the medium of pure neuronal cultures, ChAT activity increased by $101 \%$, in confirmation of the earlier finding (Fig. 7A). A more pronounced increase was observed when neurons were grown together with astrocytes. In mixed neuronal-glial cultures NGF treatment elevated ChAT activity by $318 \%$ compared with the activity in untreated cultures (Fig. $7 B$ ). The effect was specific for NGF, since the increase in ChAT activity was completely blocked by antibodies to NGF (1:500 dilution). Anti-NGF treatment alone (1:5001:125 dilution) failed to reduce ChAT activity below control levels (Fig. 7, $A$ and $B$ ).

Similarly, NGF increased AChE activity in both types of cultures. In pure neuronal selections grown for $10 \mathrm{~d}$ in the presence of NGF, AChE activity was $16 \%$ higher than in control

Table 2. Effect of NGF on fiber growth of forebrain cholinergic neurons

\begin{tabular}{lccc} 
& & & \multicolumn{2}{l}{ Increase } \\
Parameter & Control & NGF & $(\%)$ \\
\hline Number of cells/ $\mathrm{cm}^{2}$ & $3.1 \pm 0.4$ & $7.7 \pm 0.2^{a}$ & 145 \\
Total fiber length of single neuron (mm) & $4.65 \pm 0.69$ & $7.83 \pm 0.85^{a}$ & 68 \\
Branching points/neuron & $54.3 \pm 7.1$ & $76.8 \pm 9.9^{a}$ & 41 \\
Length between branching points (mm) & $0.083 \pm 0.004$ & $0.108 \pm 0.006^{a}$ & 30
\end{tabular}

Neurons of the septal region of fetal rats were grown together with glial cells in low-density cultures. NGF (100 ng/ml was present in the medium during the entire culture time. After 2-3 weeks in vitro, cultures were fixed and stained for $\mathrm{AChE}$. The number of neurons was counted, and their morphology was analyzed using a computerized image-analysis system. Means \pm SEM are given $(n=20)$.

"Significantly different from control value $(p<0.05, t$ test $)$. 

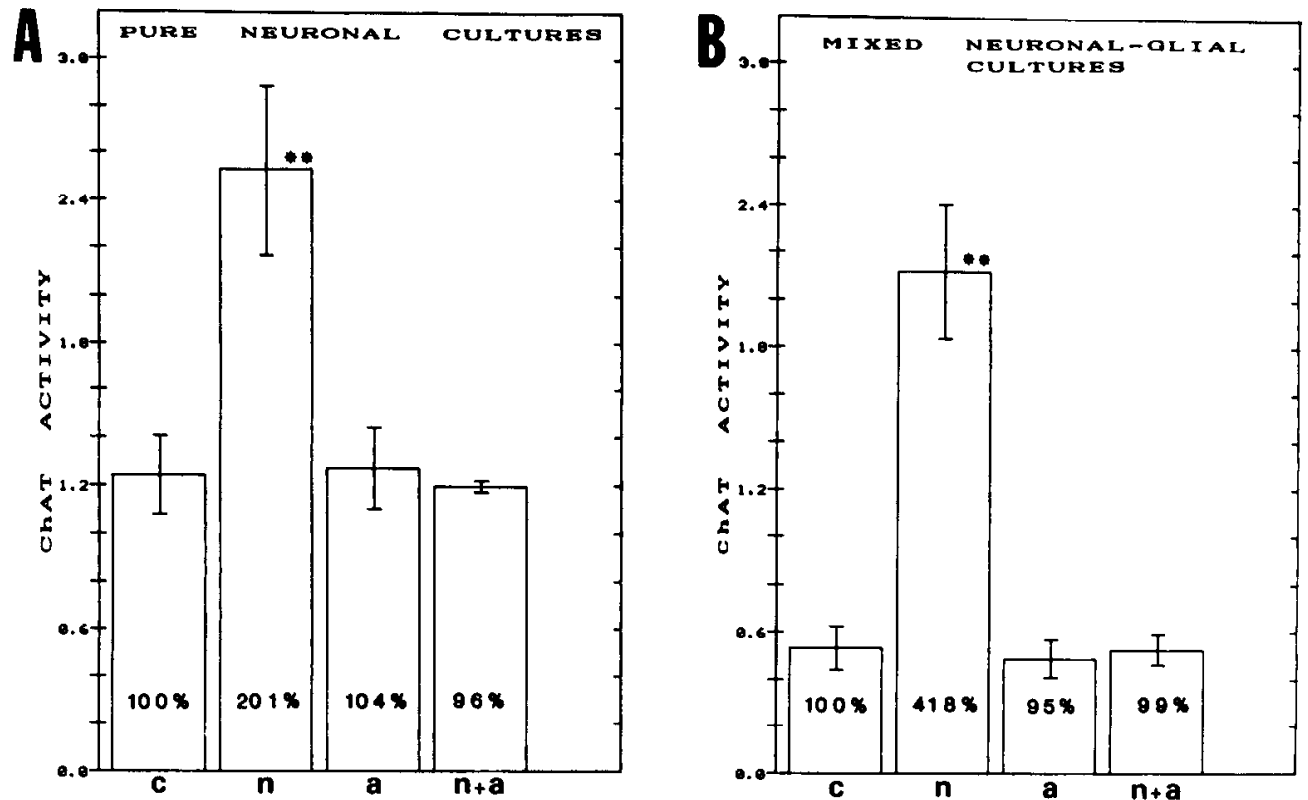

Figure 7. NGF-mediated increase in $\operatorname{ChAT}(A, B)$ and $\operatorname{AChE}(C, D)$ activity in cultures of septal neurons. Septal cells from rat fetuses (E17) were grown in high-density cultures. Proliferation of glial cells resulted in mixed neuronalglial cultures $(B, D)$. Pure neuronal cultures $(A, C)$ were obtained by treatment with cytosine arabinoside $(2-5 \mu \mathrm{M})$. Cultures were treated either with NGF $(100 \mathrm{ng} / \mathrm{ml})$ or an antiserum against NGF (1:500 dilution). After $10 \mathrm{~d}$ in vitro, the amount of protein and the activity of ChAT and AChE were determincd. ChAT and $\mathrm{AChE}$ activities are expressed as $\mathrm{pmol} / \mathrm{min} / \mu \mathrm{g}$ protein. Abbreviations: $c$, control cultures; $n$, NGF treated; $a$, anti-NGF treated; $n+a$, both NGF and anti-NGF present in the culture medium. Bars represent means \pm SEM $(n=5-8) .{ }^{*}$ Significantly different from corresponding control $(p<0.05$; ANOVA) $;{ }^{* *}$ significantly different from corresponding control $(p<0.01 ; \mathrm{AN}$ OVA).
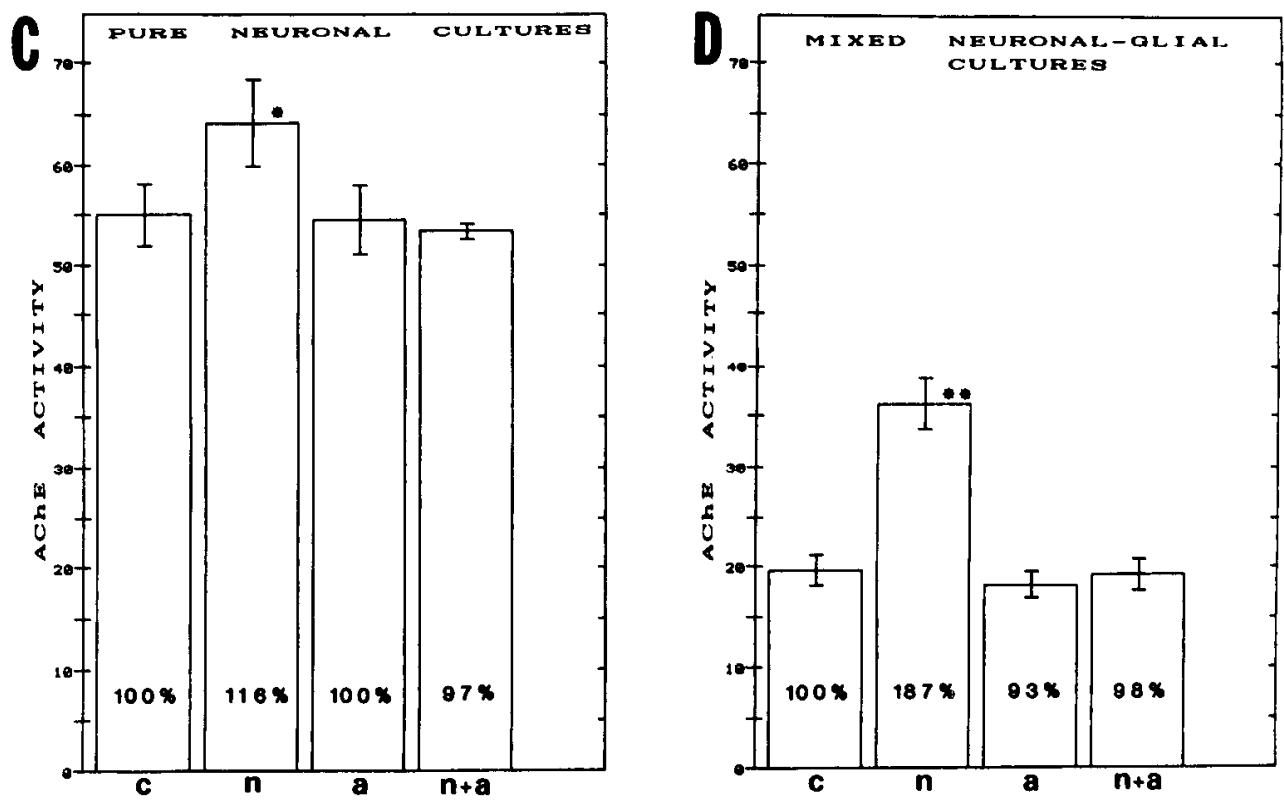

cultures (Fig. $7 \mathrm{C}$ ). Even though marginal, this increase was statistically significant (ANOVA, $p<0.05$ ). In mixed neuronalglial cultures, NGF treatment elevated AChE activity by $87 \%$ (Fig. $7 D$ ). The NGF-mediated increase in enzyme activity was blocked by antiserum against NGF, whereas antibodies themselves had no effect on AChE activity (Fig. 7, $C$ and $D$ ).

\section{Astrocytes attenuate development of ChAT and AChE activities in the absence of $N G F$}

Specific ChAT and AChE activities in mixed neuronal-glial cultures were consistently lower than enzyme activities in pure neuronal cultures of similar plating density. To resolve the question of whether this was due to a difference in survival of cholinergic neurons or in expression of these enzymes, we calculated ChAT and AChE activities per cholinergic neuron. Identical plating densities were used to prepare pure neuronal cultures and mixed neuronal-glial cultures. After $10 \mathrm{~d}$ in vitro, half of each culture type was used to determine the amount of protein and the activity of ChAT and AChE. The other half was used to determine the number of surviving cholinergic neurons using AChE cytochemistry.

Results from cell counts showed that pure neuronal cultures and mixed neuronal-glial cultures contained an equal number of AChE-positive neurons per dish (Table 3). In mixed cultures, $\mathrm{ChAT}$ and AChE activities per cholinergic neuron were significantly lower than activities in pure neuronal cultures, indicating that glial cells attenuate the expression of these 2 enzymes (Table 3). NGF treatment elevated ChAT activity to the same level (approximately $170 \mathrm{fmol} / \mathrm{min} /$ cholinergic neuron) in both types of cultures (Table 3). NGF increased ChAT activity in pure neuronal cultures and in mixed neuronal-glial cultures from 1.86 to 3.70 and from 0.71 to $3.05 \mathrm{pmol} / \mathrm{min} / \mu \mathrm{g}$ protein, respectively. These enzyme activities are comparable with those measured in vivo. The following ChAT activities have been 


\begin{tabular}{|c|c|c|c|c|c|c|}
\hline Culture & $\begin{array}{l}\text { Protein } \\
\mu \mathrm{g} \\
\text { per dish }\end{array}$ & $\begin{array}{l}\text { Cholinergic } \\
\text { neurons } \\
\text { per dish }\end{array}$ & $\begin{array}{l}\text { ChAT } \\
\mathrm{pmol} / \mathrm{min} \\
\text { per dish }\end{array}$ & $\begin{array}{l}\text { ChAT } \\
\text { fmol/min } \\
\text { per neuron }\end{array}$ & $\begin{array}{l}\text { AChE } \\
\mathrm{pmol} / \mathrm{min} \\
\text { per dish }\end{array}$ & $\begin{array}{l}\mathrm{AChE} \\
\text { fmol/min } \\
\text { per neuron }\end{array}$ \\
\hline \multicolumn{7}{|l|}{ Pure neuronal } \\
\hline Control & $125 \pm 12^{h}$ & $2937 \pm 191$ & $233 \pm 10^{\prime \prime}$ & $81 \pm 6^{\prime \prime}$ & $7057 \pm 409^{\prime \prime}$ & $2644 \pm 203^{\prime \prime}$ \\
\hline NGF & $119 \pm 12^{h}$ & $2977 \pm 197$ & $440 \pm 35^{\prime}$ & $152 \pm 14^{a}$ & $7965 \pm 531^{a . n}$ & $2931 \pm 274^{\prime \prime}$ \\
\hline Anti-NGF & $130 \pm 12^{\prime \prime}$ & $2888 \pm 182$ & $241 \pm 10^{s}$ & $84 \pm 5^{\prime \prime}$ & $7135 \pm 449^{\prime \prime}$ & $2707 \pm 195^{\prime \prime}$ \\
\hline \multicolumn{7}{|c|}{ Mixed neuronal-glial } \\
\hline Control & $168 \pm 11$ & $2637 \pm 185$ & $120 \pm 12$ & $43 \pm 2$ & $3277 \pm 224$ & $1201 \pm 41$ \\
\hline NGF & $163 \perp 11$ & $2818 \perp 239$ & $497 \perp 34^{a}$ & $176 \perp 13^{\prime \prime}$ & $5912 \perp 527^{a}$ & $2007 \perp 138^{\prime \prime}$ \\
\hline Anti-NGF & $173 \pm 11$ & $2655 \pm 172$ & $119 \pm 10$ & $43 \pm 2$ & $3231 \pm 177$ & $1197 \pm 48$ \\
\hline
\end{tabular}

Neurons of the septal region of fetal rats were grown in high-density cultures. Identical plating densities were used to prepare pure neuronal cultures and mixed neuronal-glial cultures. Cultures were treated either with $\mathrm{NGF}(100 \mathrm{ng} / \mathrm{ml})$ or with a sheep antiserum against NGF (1:500 dilution). After $10 \mathrm{~d}$ in vitro, half of each culture type was used to determine the amount of protein and the activity of ChAT and AChE. The other half was used to determine the number of surviving cholinergic neurons using AChE cytochemistry. Means \pm SEM are given $(n=4-6)$.

" $p<0.05$, compared with untreated control cultures ( $t$ test).

" $p<0.05$, compared with corresponding value in mixed neuronal-glial cultures ( $t$ test).

reported in the septal area of neonatal rats: $0.28-0.95 \mathrm{pmol} /$ $\mathrm{min} / \mu \mathrm{g}$ protein for untreated rats and $0.48-2.88 \mathrm{pmol} / \mathrm{min} / \mu \mathrm{g}$ protein for rats that received intraventricular injections of NGF during their first postnatal week (Gnahn et al., 1983; Mobley et al., 1986). NGF increased AChE activity in both types of cultures. Unlike the case of ChAT activity, AChE activity per cholinergic neuron remained significantly lower in mixed cultures than in pure neuronal culture even after NGF treatment (Table 3). The results suggest that the presence of glial cells is not required for survival and differentiation of septal neurons in short-term cultures. Astrocytes even seem to attenuate development of cholinergic properties. However, NGF is able to increase $\mathrm{ChAT}$ activity to the same maximal level in both types of cultures.

\section{Identification of living cholinergic neurons in septal cultures}

When cultured together with glial cells, neurons survived longer than in pure neuronal cultures. We frequently observed very large neurons (diameter of the cell body $25-30 \mu \mathrm{m}$ ) in mixed neuronal-glial cultures grown for 3 weeks or more. These neurons had a strong halo surrounding the round cell body, and they seemed to grow on top of a glial feeder layer (Fig. 8). The number of these neurons was greatly increased when cultures were treated with NGF. We tested the hypothesis that these large round cells are cholinergic neurons. Two hundred and seventeen cells were marked in living cultures by making a ring around the neuron in the plastic culture dish. Thereafter, cultures were fixed and stained either for AChE cytochemistry or NGF-R immunocytochemistry. Ninety-five neurons out of 110 previously identified large cells (86\%) contained AChE; 98 neurons out of 107 marked cells $(92 \%)$ were positively stained in NGF-R immunocytochemistry. This is in agreement with an earlier report demonstrating that, in cultures of dissociated cells from newborn rat basal forebrain, $75 \%$ of the large neurons contain either ChAT or AChE (Nakajima et al., 1985). Our results indicate that living cholinergic neurons, grown in cultures of dissociated septal cells, can be reliably identified in NGFtreated cultures according to the size of the cell body. This observation should facilitate studies of the electrophysiological properties of basal forebrain cholinergic neurons and of factors that affect the expression of neurotransmitter receptors and ion channels by these cells.

\section{Discussion}

We established a culture system to study the effects of NGF on survival, fiber growth, and differentiation of basal forebrain cholinergic neurons. Using this system, we demonstrated that NGF-R are selectively expressed by cholinergic neurons. NGF was shown to promote survival, fiber growth, and expression of ChAT and AChE. Quality and extent of the NGF effect depended upon the culture system used and were influenced particularly by the presence of astrocytes and the plating density. $\Lambda$ strocytes were shown to attenuate the expression of ChAT and AChE in the absence of NGF. Finally, we established a procedure to identify cholinergic neurons in living cultures.

\section{Cholinergic neurons in culture}

In our attempt to study cholinergic neurons in vitro, the initial goal was to prepare cultures containing only the cholinergic neurons of rat septum. First, we tested whether NGF can selectively keep alive forebrain cholinergic neurons under culture conditions in which all other neurons degenerate. We found that the survival of cholinergic neurons was dependent on the survival of the other neurons and that the presence of NGF in our culture medium was insufficient for survival of the cholinergic neurons. Second, we tried to purify septal neurons using gradient centrifugation, i.e., a method that was successfully used to enrich cholinergic motoneurons of mouse and rat spinal cord (Schnaar and Schaffner, 1981). This method produced only a 2- to 3-fold purification of cholinergic neurons, which was judged unsatisfactory for further experiments. Third, we attempted retrograde labeling and fluorescence-activated cell sorting, i.e., a method used to enrich chick motoneurons (O'Brien and Fischbach, 1986). Fluorescent dyes were injected into the hippocampus of 2- to 3 -d-old rats, and cultures of dissociated septal cells were prepared $48 \mathrm{hr}$ after the injection. In these cultures, a few living neurons carried a fluorescent label, indicating that they had an axonal connection to the hippocampus at the time of injection. Low yield of viable cells obtained from neonatal brain, however, made further experiments impractical. 


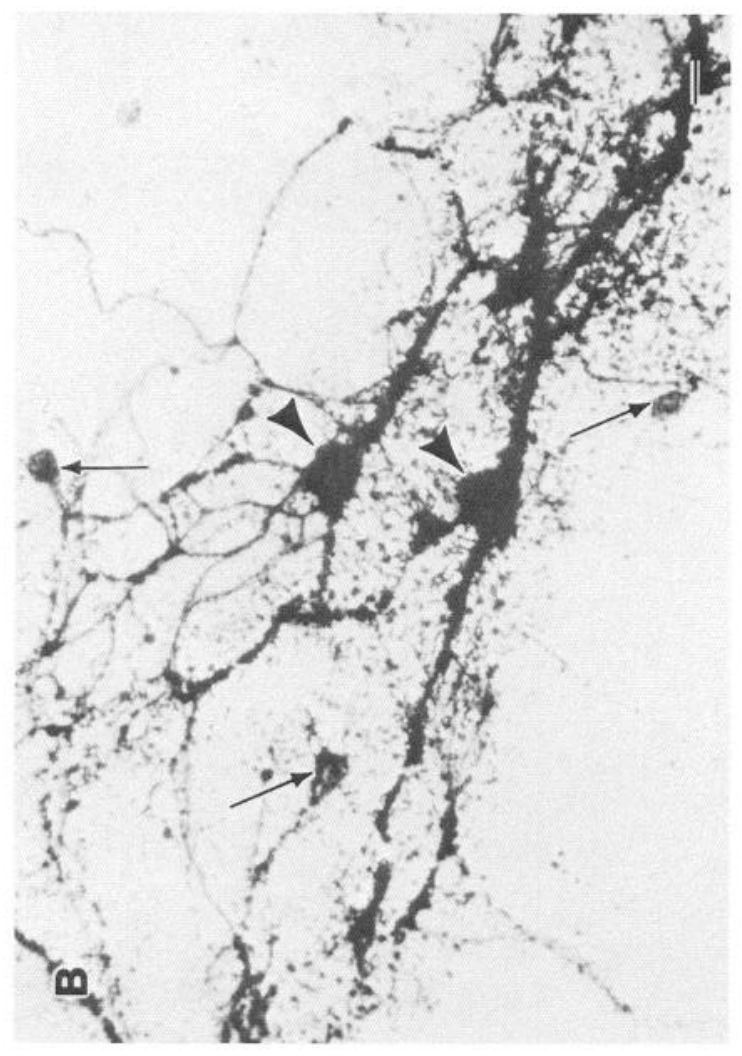

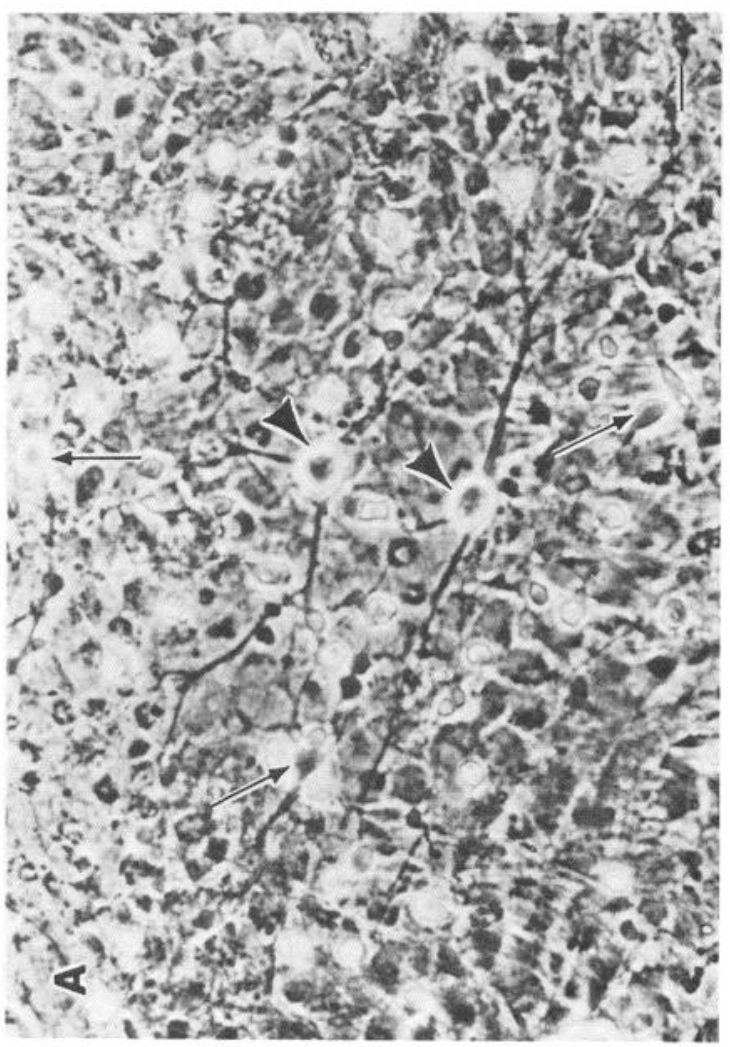

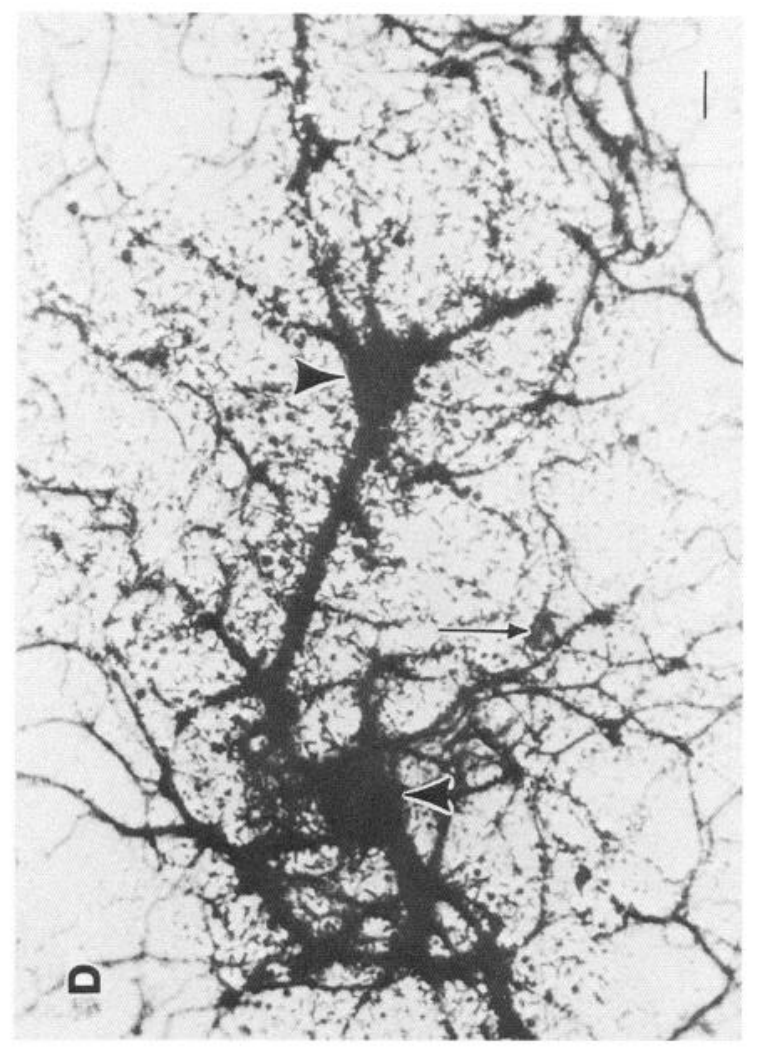

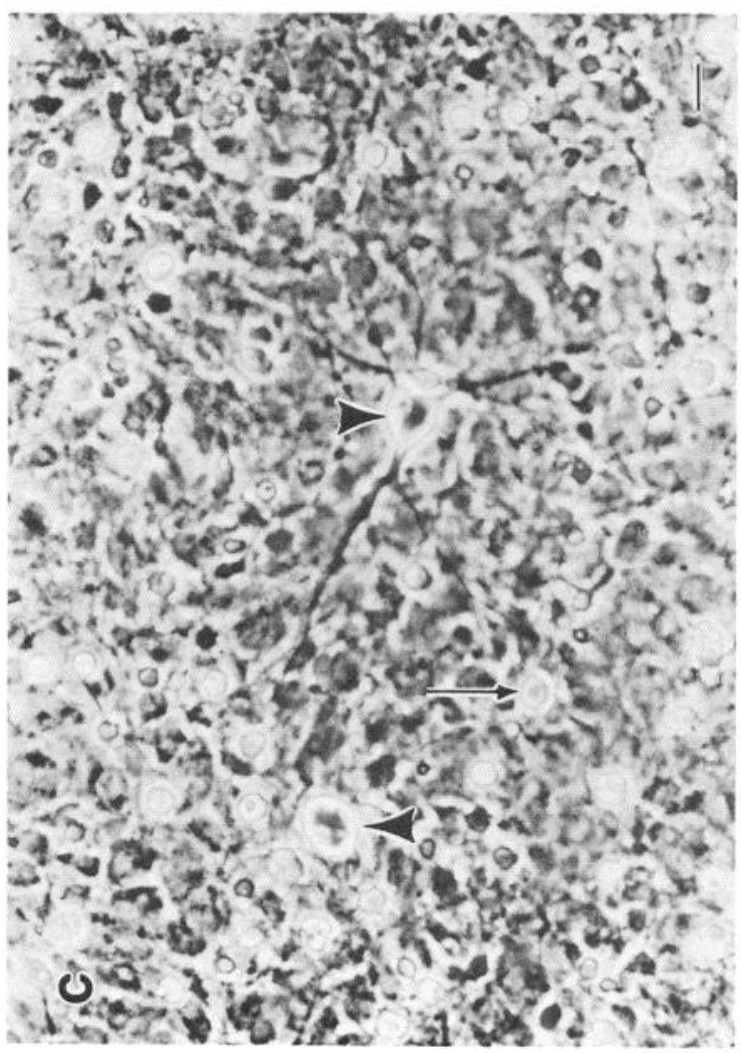

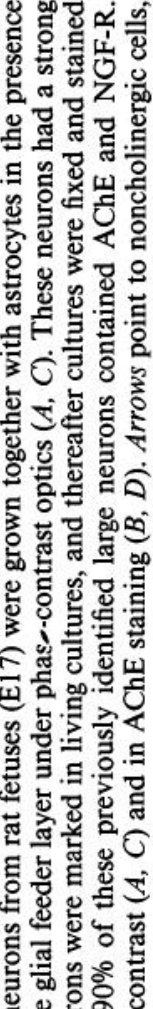

닐인

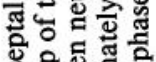

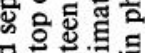

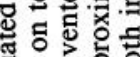

궁

记它

웅

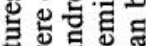

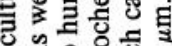

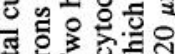

彭证

造宁 向

코욜

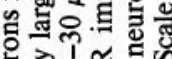

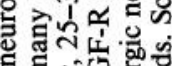

के

氖昰。융

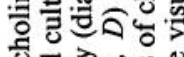

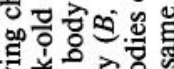

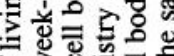

○

드의 혀웜

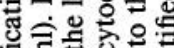

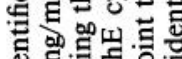

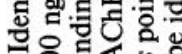

- 을젼

$\infty$ 녕 해

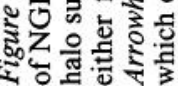


Given the difficulty encountered in preparing cultures containing cholinergic neurons only, we decided to study the effects of NGF on these neurons in cultures also containing other neuronal populations and glial cells. To distinguish direct effects on ncurons from cffects mediatcd through glial cells, we developed 2 different culture systems: first, cultures in which septal neurons grew together with astrocytes and, second, cultures in which these neurons grew in an essentially glial-free environment. In our earlier studies, we used high plating densities and a modified L-15 medium containing high concentrations of glucose and amino acids, resulting in maximal survival of all septal cells, including cholinergic neurons. Under these culture conditions, only 4 treatments specifically affected ChAT activity of cholinergic neurons: NGF (Hefti et al., 1985a), gangliosides (Hefti et al., 1985b), thyroxine (Hefti et al., 1986a), and depolarization with elevated $\mathrm{K}^{+}$concentrations (unpublished observations). The ganglioside-induced increase in ChAT activity appeared to be secondary to attenuation of astrocytic proliferation in septal cultures. Conditioned medium from cultures containing cortical neurons, hippocampal neurons, or astrocytes did not increase the specific ChAT activity in our septal cultures. Similarly, cocultivation of septal cells together with hippocampal cells did not affect the growth and ChAT expression of cholinergic neurons (unpublished findings).

\section{Survival and fiber growth of cholinergic neurons}

Our finding that plating density influences the general survival of septal neurons in culture and that culture density affects the response of cholinergic neurons to exogenous NGF are in line with results of Barbin et al. (1984), who reported that lowdensity cultures of dissociated CNS neurons degenerate rapidly unless trophic factors are added to the medium. High-density cultures were found to survive in the absence of exogenous trophic agents, and conditioned medium from high-density cultures was able to support survival of CNS neurons grown in low-density cultures (Barbin et al., 1984). We have earlier demonstrated that the specific ChAT activity in pure neuronal cultures of septal cells rises with increasing cell density (Hefti et al., 1985a). These results suggest that the cells in low-density cultures are not able to produce sufficient amounts of endogenous survival and growth factors. Alternatively, direct cell-cell interactions might be important for survival and differentiation of neurons in vitro. Acheson and Thoenen (1983) have shown that direct cell-cell contact, rather than a diffusible factor, clevates the expression of tyrosine hydroxylase in cultures of bovine adrenal chromaffin cells.

The present report demonstrates for the first time that NGF affects survival of basal forebrain cholinergic neurons in cultures of dissociated fetal cells and supports results obtained in vivo, where NGF has been found to increase survival of septal cholinergic neurons after axonal injury (Hefti, 1986; Williams et al., 1986; Kromer, 1987). The finding that NGF increases and anti-NGF decreases the number of cholinergic neurons surviving in low-density cultures suggests that NGF is formed in these cultures by neurons or glial cells, or both, in sufficient quantities to support the survival of an intermediate number of cholinergic neurons in untreated control cultures. This notion is consistent with results showing that human, rat, and mouse brain astrocytes grown in culture synthesize and secrete NGF (Lindsay, 1979; Norrgren et al., 1980; Furukawa et al., 1986).

Contrary to the results obtained with low-density cultures,
NGF and anti-NGF did not affect the number of cholinergic neurons in high-density cultures. Anti-NGF was ineffective even in pure neuronal cultures, for which one can neglect the possibility that NGF is synthesized and released by astrocytes in sufficient quantitics. The inability of anti-NGF to decrease biochemically measurable ChAT and AChE activities below control levels gives further support to the notion that anti-NGF treatment does not affect survival of cholinergic neurons in highdensity cultures. The results are in agreement with those of other studies showing that anti-NGF fails to reduce ChAT activity of basal forebrain cholinergic neurons, both in vivo (Gnahn et al., 1983) and in vitro (Hefti et al., 1985a; Hatanaka and Tsukui, 1986; Martinez et al., 1987). Two different hypotheses explain the inability of anti-NGF to affect survival of cholinergic neurons in vivo or in high-density cultures. First, because of limited penetration, anti-NGF might not bind and inactivate NGF produced in the brain or in cultures. In vivo it has been demonstrated that anti-NGF antibodies can diffuse only a distance of $1 \mathrm{~mm}$ from the injection site (Springer and Loy, 1985). High cell density in our septal cultures might prevent the penetration of antibodies close to the cells that synthesize NGF. Second, there might be other growth factors that affect survival of cholinergic neurons and replace NGF as a survival factor. These other neurotrophic factors could be synthesized by other cells and might reach sufficiently high levels in high-density cultures, resulting in maximal survival of cholinergic neurons in the absence of NGF. NGF might become an essential survival factor for basal forebrain cholinergic neurons in low-density cultures only, where growth conditions are not optimal, or after axonal injury in vivo.

Our present observation that NGF increases fiber growth of cholinergic neurons is in apparent contradiction with our earlier report (Hefti et al., 1985a). In the earlier studies, we measured the number of proximal processes at a distance of $90 \mu \mathrm{m}$ from the cell body of cholinergic neurons and found that NGF or anti-NGF did not affect this parameter. In the present study, an improved staining procedure was used, resulting in visualization of the entire network of cholinergic fibers. Using this method, we found that NGF increases the total length of fibers of a given cholinergic neuron. In agreement with the earlier studies, the number of proximal processes was found to be unchanged (data not shown). The effect of NGF on fiber growth could be quantified only in mixed neuronal-glial cultures of low plating density. However, visual inspection of high-density cultures strongly suggested that NGF also affects fiber growth of cholinergic neurons in high-density cultures.

The findings of the present study support the view that NGF plays a role in the development of the septohippocampal projection in vivo. This projection is established between fetal day 20 and postnatal day 14 in the rat brain (Milner et al., 1983). High levels of NGF and mRNA NGF have been measured in the hippocampus of fetal and neonatal rats (Large et al., 1986; Whittemore et al., 1986, 1987; Auburger et al., 1987). Similarly, both NGF-R and mRNA coding for this protein can be detected in the basal forebrain of pre- and postnatal rats (Loy and Koh, 1986; Buck et al., 1987). These results demonstrate that NGF is synthesized in rat hippocampus and NGF-R are expressed in the basal forebrain during the time period when septal cholinergic fibers invade the hippocampus. We have now demonstrated that NGF increases fiber growth of basal forebrain cholinergic neurons in dissociated cultures of fetal rat septum. Accordingly, 
it has been shown that NGF stimulates growth of cholinergic fibers in cocultures of septal and hippocampal slices of neonatal rats (Gähwiler et al., 1987). These results suggest that, during development of the rat brain, NGF produced by hippocampal cells stimulates the growth of cholinergic axons from the septum into the hippocampus.

It is still unclear whether NGF, besides its well-established role as a trophic factor for forebrain cholinergic neurons, is involved in the function of other central populations of neurons. Based on the immunohistochemical visualization of NGF-R, cholinergic neurons of the basal forebrain seem to be the only cells containing these receptors in the adult brain. No NGF-R were found in cholinergic interneurons of human caudate nucleus and putamen (Hefti et al., 1986b) or in rat striatum (see fig. 1 in Springer et al., 1987). During development of the CNS, however, NGF seems to play a broader role and also to affect other neuronal populations than basal forebrain cholinergic neurons. Cholinergic interneurons of the corpus striatum of fetal and neonatal rats were reported to respond to NGF with a dosedependent increase in ChAT activity (Martinez et al., 1985; Mobley et al., 1985). Furthermore, detectable levels of NGF protein and NGF mRNA were found in diencephalon and cerebellum, despite the lack of major cholinergic innervation to these areas (Large et al., 1986; Shelton and Reichardt, 1986). Finally, NGF-receptor-like immunoreactivity was shown to exist in several regions of rat brain during specific pre- and postnatal developmental stages, in addition to the expected staining in the basal forebrain (Eckenstein, 1988).

\section{Effect of astrocytes and NGF on ChAT and AChE activity}

The presence of astrocytes was nol required for survival and growth of cholinergic neurons in cultures of septal cells plated at high density. Our results demonstrating that fetal CNS neurons survive and differentiate in vitro up to 2 weeks in the absence of astrocytes are in line with those of a recent report by Aizenman and de Vellis (1987), who showed that fetal cortical neurons differentiate in a chemically defined medium in a glial-free environment.

We earlier reported that attenuation of astrocytic proliferation with gangliosides increases the specific $\mathrm{Ch} \Lambda \mathrm{T}$ activity in cultures of septal cells (Hefti et al., 1985b). In the present study, similar increases in ChAT and AChE activities were measured in cultures after inhibition of astrocytic growth by cytotoxic compounds. A similar effect has been reported in aggregating cell cultures of fetal rat telenecephalon, in which Ara-C treatment increased the total ChAT activity (Honegger et al., 1986). These results suggest that the presence of astrocytes attenuates the expression of cholinergic marker enzymes. By suppressing the development of transmitter-specific properties, astrocytes might favor the structural development of the cholinergic cells. Alternatively, the reduction of astrocyte number might favor neuronneuron interactions and, by an unknown mechanism, result in elevated ChAT and AChE activities. Furthermore, proliferating astrocytes might physically interfere with fiber growth of cholinergic neurons. In cell cultures of dissociated neurons, astrocytes appear to grow underneath neurons and might detach neuronal processes from the surface of the culture dish.

The findings of the present study confirm that NGF stimulates the expression of ChAT and AChE activities by cultured cholinergic neurons. NGF-mediated increases in $\mathrm{AChE}$ activity were previously found in pure neuronal cultures of dissociated septal cells (Hefti et al., 1985a) and in explant cultures of fetal medial septal nuclei (Martinez et al., 1987). NGF-mediated increases in ChAT activity were found in various culture systems containing basal forebrain cholinergic neurons (Honegger and Lenoir, 1982; Gnahn et al., 1983; Hefti et al., 1985a; Hatanaka and Tsukui, 1986; Honegger et al., 1986; Mobley et al., 1986; Martinez et al., 1987). We earlier showed that NGF has to be present in the medium of septal cultures for a minimal period of $3 \mathrm{~d}$ to elevate ChAT activity, suggesting that the NGF-mediated increase in ChAT activity reflects an increased synthesis of this enzyme rather than an activation of existing molecules (Hefti et al., 1985a). Thus far, it has been unclear whether the increase in ChAT and AChE activities is due to increased survival, fiber growth, or an increase in enzyme expression. In the present study, NGF was found to increase these enzyme activities in high-density cultures, in which NGF does not affect the survival of cholinergic neurons. Part of the increase in ChAT and AChE activities in these cultures is probably due to an increase in volume of cholinergic cell bodies, as suggested by results from ChAT immunocytochemistry. Furthermore, it is likely that NGF increases fiber growth of cholinergic neurons also in high-density cultures as demonstrated in low-density cultures. Increases in the size of both the cell body and the fiber network elevate the volume of cholinergic neurons, resulting in a greater number of ChAT and AChE molecules in NGF-treated cultures. However, NGF always increased ChAT activity to a much greater extent than AChE activity, suggesting that NGF selectively increases the synthesis of new ChAT molecules.

The NGF-mediated increases in ChAT and AChE activities are greatly influenced by the presence of astrocytes. Even though the percentage increase in ChAT activity was greater in mixed neuronal-glial cultures than in pure neuronal cultures, NGF treatment elevated ChAT activity to the same maximal level in both types of cultures. The difference in the percentage increase was due to the fact that basal levels of ChAT were lower in untreated mixed neuronal-glial cultures than in pure neuronal cultures. Our results, therefore, suggest that the NGF-mediated increases in ChAT and AChE activities are not mediated by glial cells and that astrocytes attenuate the expression of cholinergic marker enzymes in the absence of NGF.

\section{Regulation of $N G F-R$ expression by cholinergic neurons}

Two different types of NGF-R have been found to occur in most tissues and cells studied. Type I receptors are characterized by fast dissociation of NGF and relatively low affinity $\left(K_{D}, 10^{-9} \mathrm{M}\right)$, and type II receptors are characterized by slow rate of dissociation and relatively high affinity $\left(K_{D} 10^{-11} \mathrm{M}\right)$. Both human and rat low-affinity NGF-R have been cloned and sequenced (Johnson et al., 1986; Radeke et al., 1987). Northern blot analysis has shown that there is only a single mRNA species for NGF-R in rat basal forebrain, in sympathetic and sensory ganglia, and in PC12 cells (Buck et al., 1987; Radeke et al., 1987). However, binding studies have demonstrated that sympathetic and sensory ganglia and $\mathrm{PC} 12$ cells express both types of receptors. These results are compatible with the view that fast, type I receptors are converted into slow, type II receptors and that they represent 2 functional states of a single protein. The monoclonal antibody 192-IgG against rat NGF-R has been shown to recognize both types of receptors in PCl 2 cells (Green and Greene, 1986).

Using antibody $192-\mathrm{IgG}$ we have now demonstrated that NGF$R$ are exclusively located on cholinergic neurons in septal cultures. It is not clear whether the population of cholinergic neu- 
rons not stained for NGF-R (21\%) have not reached the threshold of visibility or whether they indeed represent a subpopulation not expressing the receptors. NGF treatment increases the staining intensity and the number of NGF-R-positive neurons in high-density cultures, in which NGF does not affect the survival of cholinergic neurons. This observation therefore suggests that exposure of basal forebrain cholinergic neurons to NGF stimulates the expression of NGF-R. This is in agreement with the previous studies of Bernd and Greene (1984), who found that NGF-treated PC12 cells had a 4-fold higher number of lowand high-affinity NGF-R than control cells. Furthermore, chick sensory neurons in culture, which normally express NGF-R during a limited period of time only, have been found to maintain their NGF-R when grown in presence of NGF (Rohrer and Barde, 1982). It has also been reported that epidermal growth factor and interleukin 2 can directly stimulate transcription and expression of their own receptor (Clark et al., 1985; Depper et al., 1985). The ability of NGF to upregulate the expression of its own receptor might explain why forebrain cholinergic neurons, projecting to areas with high NGF levels, remain responsive to NGF during the entire life span, whereas other central neurons expressing NGF-R at early developmental stages but not projecting to areas with high NGF levels lose their responsiveness.

Note added in proof: In agreement with the findings of the present study, Hatanaka et al. (1988) recently reported that NGF promotes survival of cultured basal forebrain cholinergic neurons from postnatal rats. Our additional findings (Table 1), however, indicate that NGF's ability to stimulate survival is a function of plating density rather than the age of the tissue used to prepare the cultures as suggested by Hatanaka et al.

\section{References}

Acheson, A. L., and H. Thoenen (1983) Cell contact-mediated regulation of tyrosine hydroxylase synthesis in cultured bovine adrenal chromaffin cells. J. Cell Biol. 97: 925-928.

Aizenman, Y., and J. de Vellis (1987) Brain neurons develop in a serum and glial free environment: Effects of transferrin, insulin, insulin-like growth factor-I and thyroid hormone on neuronal survival, growth and differentiation. Brain Res. 406: 32-42.

Auburger, G., R. Heumann, R. Hellweg, S. Korsching, and H. Thoenen (1987) Developmental changes of nerve growth factor and its mRNA in the rat hippocampus: Comparison with choline acetyltransferase. Dev. Biol. 120: 322-328

Barbin, G., I. Selak, M. Manthorpe, and S. Varon (1984) Use of central neuronal cultures for the detection of neuronotrophic agents. Neuroscience 12: 33-43.

Bayer, S. A. (1979) The development of the septal region in the rat. I. Neurogenesis examined with ${ }^{3} \mathrm{H}$-thymidine autoradiography. J. Comp. Neurol. 183: 89-106.

Bernd, P., and L. A. Greene (1984) Association of ${ }^{125}$ I-nerve growth factor with PC12 pheochromocytoma cells. Evidence for internalization via high-affinity receptors only and for long-term regulation by nerve growth factor of both high- and low-affinity receptors. J. Biol. Chem. 259: 15509-15516.

Bocchini, V., and P. U. Angeletti (1969) The nerve growth factor: Purification as 30,000-molecular-weight protein. Proc. Natl. Acad. Sci. USA 64: 787-794

Bradford, M. M. (1976) A rapid and sensitive method for the quantitation of microgram quantities of protein utilizing the principle of protein-dye binding. Anal. Biochem. 72: 248-254.

Buck, C. R., H. J. Martinez, I. B. Black, and M. V. Chao (1987) Developmentally regulated expression of the nerve growth factor receptor gene in the periphery and brain. Proc. Natl. Acad. Sci. USA 84: 3060-3063.

Chandler, C. E., L. M. Parsons, M. Hosang, and E. M. Shooter (1984)
A monoclonal antibody modulates the interaction of nerve growth factor with PC12 cells. J. Biol. Chem. 259: 6882-6889.

Clark, A. J. L., S. Ishii, N. Richert, G. T. Merlino, and I. Pastan (1985) Epidermal growth factor regulates the expression of its own receptor. Proc. Natl. Acad. Sci. USA 82: 8374-8378.

Depper, J. M., W. J. Leonard, C. Drogula, M. Krönke, T. A. Waldmann, and W. C. Greene (1985) Interleukin 2 (IL-2) augments transcription of the IL-2 receptor gene. Proc. Natl. Acad. Sci. USA 82: 4230-4234.

Dreyfus, C. F., E. R. Peterson, and S. M. Crain (1980) Failure of nerve growth factor to affect fetal mouse brain stem catecholaminergic neurons in culture. Brain Res. 194: 540-547.

Eckenstein, F. (1988) Transient expression of NGF-receptor-like immunoreactivity in postnatal rat brain and spinal cord. Brain Res. 446 : $149-154$

Eckenstein, F., and M. W. Sofroniew (1983) Identification of central cholinergic neurons containing both choline acetyltransferase and acetylcholinesterase and of central neurons containing only acetylcholinesterase. J. Neurosci. 3: 2286-2291.

Eckenstein, F., and H. Thoenen (1982) Production of specific antiserum and monoclonal antibodies to choline acetyltransferase: Characterization and use for identification of cholinergic neurons. EMBO J. 1: 363-368.

Fonnum, F. (1975) A rapid radiochemical method for the determination of choline acetyltransferase. J. Neurochem. 24: 407-409.

Furukawa, S., Y. Furukawa, E. Satoyoshi, and K. Hayashi (1986) Synthesis and secretion of nerve growth factor by mouse astroglial cells in culture. Biochem. Biophys. Res. Commun. 136: 57-63.

Gähwiler, B. H., A. Enz, and F. Hefti (1987) Nerve growth factor promotes development of the rat septo-hippocampal cholinergic projection in vitro. Neurosci. Lett. 75: 6-10.

Geneser-Jensen, F. A., and T. E. Blackstadt (1971) Distribution of acetylcholinesterase in the hippocampal region of the guinea pig. I. Entorhinal area, parasubiculum, and pre-subiculum. Z. Zellforsch. 114: 460-481.

Gnahn, H., F. Hefti, R. Heumann, M. E. Schwab, and H. Thoenen (1983) NGF-mediated increase of choline acetyltransferase (ChAT) in the neonatal forebrain: Evidence for a physiological role of NGF in the brain? Dev. Brain Res. 9:45-52.

Green, S. H. and L. A. Greene (1986) A single Mr $=103,000$ 125Ibeta-nerve growth factor-affinity-labeled species represents both the low and high affinity forms of the nerve growth factor receptor. J. Biol. Chem. 261: 15316-15326.

Hartikka, J., and F. Hefti (1985) Forebrain cholinergic neurons survive and differentiate in culture in the absence of astrocytes. Soc. Neurosci. Abstr. 11: 1147.

Hartikka, J., and F. Hefti (1986) Effect of nerve growth factor on septal cholinergic neurons in mixed glial-neuronal cultures. Soc. Neurosci. Abstr. 12: 1099.

Hatanaka, H., and H. Tsukui (1986) Differential effects of nerve growth factor and glioma-conditioned medium on neurons cultured from various regions of fetal rat central nervous system. Dev. Brain Res. 30: $47-56$.

Hatanaka, H., H. Tsukui, and I. Nihonmatsu (1988) Developmental change in the nerve growth factor action from induction of choline acetyltransferase to promotion of cell survival in cultured basal forebrain cholinergic neurons from postnatal rats. Dev. Brain Res. 39: $85-95$.

Hefti, F. (1986) Nerve growth factor (NGF) promotes survival of septal cholinergic neurons after fimbrial transection. J. Neurosci. 6: 21552162.

Hefti, F., A. Dravid, and J. Hartikka (1984) Chronic intraventricular injections of nerve growth factor elevate hippocampal choline acetyltransferase activity in adult rats with partial septo-hippocampal lesions. Brain Res. 293: 305-311.

Hefti, F., J. Hartikka, F. Eckenstein, H. Gnahn, R. Heumann, and M. E. Schwab (1985a) Nerve growth factor increases choline acetyltransferase but not survival or fiber outgrowth of cultured fetal septal cholinergic neurons. Neuroscience 14: 55-68.

Hefti, F., J. Hartikka, and W. Frick (1985b) Gangliosides alter morphology and growth of astrocytes and increase the activity of choline acetyltransferase in cultures of dissociated septal cells. J. Neurosci 5(8): 2086-2094

Hefti, F., J. Hartikka, and M. B. Bolger (1986a) Effect of thyroid hormone analogs on the activity of choline acetyltransferase in cultures of dissociated septal cells. Brain Res. 375: 413-416. 
Hefti, F., J. Hartikka, A. Salvatierra, W. J. Weiner, and D. C. Mash (1986b) Localization of nerve growth factor receptors in cholinergic neurons of the human basal forebrain. Neurosci. Lett. 69: 37-41.

Hefti, F., J. Hartikka, and J. Sanche $z$-Ramos (1987) Cholinergic neurons of the basal forebrain in culture. In Cell Culture Techniques in Neurobiology, A. Shahar and B. Haber, eds. (in press).

Honegger, P., and D. Lenoir (1982) Nerve growth factor (NGF) stimulation of cholinergic telencephalic neurons in aggregating cell cultures. Dev. Brain Res. 3: 229-238.

Honegger, P., P. DuPasquier, and M. Tenot (1986) Cholinergic neurons of fetal rat telencephalon in aggregating cell culture respond to NGF as well as to protein kinase C-activating tumor promoters. Dev. Brain Res. 29: 217-223.

Inagaki, S., M. Sakanaka, S. Shiosaka, E. Senba, H. Takatuski, H. Tagagi, Y. Kawai, H. Minagawa, and M. Tohyama (1982) Ontogeny of substance P-containing neuron system of the rat: Immunohistochemical analysis. I. Forebrain and upper brain stem. Neuroscience 7: 251-277.

Johnson, C. D., and R. L. Russell (1975) A rapid, simple radiometric assay for cholinesterase, suitable for multiple determinations. Anal. Biochem. 64: 229-238.

Johnson, D., A. Lanahan, C. R. Buck, A. Sehgal, C. Morgan, E. Mercer, M. Bothwell, and M. Chao (1986) Expression and structure of the human NGF receptor. Cell 47: 545-554.

Konkol, R. J., R. Mailman, E. G. Bendeich, A. M. Garrison, R. A. Mueller, and G. R. Breese (1978) Evaluation of the effects of nerve growth factor and anti-nerve growth factor on the development of central catecholamine-containing neurons. Brain Res. 144: 277-285.

Korsching, S., G. Auburger, R. Heumann, J. Scott, and H. Thocncn (1985) Levels of nerve growth factor and its mRNA in the central nervous system of the rat correlate with cholinergic innervation. EMBO J. 6: 1389-1393.

Kromer, L. F. (1987) Nerve growth factor treatment after brain injury prevents neuronal death. Science 235: 214-216.

Large, T. H., S. C. Bodary, D. O. Clegg, G. Weskamp, U. Otten, and L. F. Reichardt (1986) Nerve growth factor gene expression in the developing rat brain. Science 234: 352-355.

Levey, A. I., B. H. Wainer, E. J. Mufson, and M. M. Mesulam (1983) Co-localization of acetylcholinesterase and choline acetyltransferase in the rat cerebrum. Neuroscience 9:9-22.

Levi-Montalcini, R. (1982) Developmental neurobiology and the natural history of nerve growth factor. Annu. Rev. Neurosci. 5: $341-$ 362.

Lindsay, R. M. (1979) Adult rat brain astrocytes support survival of both NGF-dependent and NGF-insensitive neurons. Nature 282: 8082.

Mains, R. E., and P. H. Patterson (1973) Primary cultures of dissociated sympathetic neurons. I. Establishment of long-term growth in culture and studies of differentiated properties. J. Cell Biol. 59: 329345.

Manthorpe, M., R. Adler, and S. Varon (1979) Development, reactivity and GFA immunofluorescence of astroglia-containing monolayer cultures from rat cerebrum. J. Neurocytol. 8: 605-621.

Martinez, H. J., C. F. Dreyfus, G. M. Jonakait, and I. B. Black (1985) Nerve growth factor promotes cholinergic development in brain striatal cultures. Proc. Natl. Acad. Sci. USA 82: 7777-7781.

Martinez, H. J., C. F. Dreyfus, G. M. Jonakait, and I. B. Black (1987) Nerve growth factor selectively increases cholinergic markers but not neuropeptides in rat basal forebrain in culture. Brain Res. 412: 295301.

Mesulam, M. M., E. J. Mufson, A. I. Levey, and B. H. Wainer (1983a) Cholinergic innervation of cortex by the basal forebrain: Cytochemistry and cortical connections of the septal area, diagonal band nuclei, nucleus basalis (substantia innominata), and hypothalamus in the rhesus monkey. J. Comp. Neurol. 214: 170-197.

Mesulam, M. M., E. J. Mufson, B. H. Wainer, and A. I. Levey (1983b) Central cholinergic pathways in the rat: An overview based on an alternative nomenclature (Ch1-Ch6). Neuroscience 10: 1185-1201.

Mesulam, M. M., E. J. Mufson, A. I. Levey, and B. H. Wainer (1984) Atlas of cholinergic neurons in the forebrain and upper brainstem of the macaque based on monoclonal choline acetyltransferase immunohistochemistry and acetylcholinesterase histochemistry. Neuroscience 12: 669-686.

Milner, T. A., R. Loy, and D. G. Amáral (1983) An anatomical study of the development of the septo-hippocampal projection in the rat. Dev. Brain Res. 8: 343-371.

Mobley, W. C., J. L. Rutkowski, G. I. Tennekoon, K. Buchanan, and M. V. Johnston (1985) Choline acetyltransferase activity in striatum of neonatal rats increased by nerve growth factor. Science 299: $284-$ 287.

Mobley, W. C., J. L. Rutkowski, G. I. Tennekoon, J. Gemski, K. Buchanan, and M. V. Johnston (1986) Nerve growth factor increases choline acetyltransferase activity in developing basal forebrain neurons. Mol. Brain Res. 1: 53-62.

Nakajima, Y., S. Nakajima, K. Obata, C. G. Carlson, and K. Yamaguchi (1985) Dissociated cell culture of cholinergic neurons from nucleus basalis of Meynert and other basal forebrain nuclei. Proc. Natl. Acad. Sci. USA 82: 6325-6329.

Norrgren, G., T. Ebendal, M. Belew, C. O. Jacobson, and J. Porath (1980) Release of nerve growth factor by human glial cells in culture. Exp. Cell Res. 130: 31-39.

O'Brien, R. J., and G. D. Fischbach (1986) Isolation of embryonic chick motoneurons and their survival in vitro. J. Neurosci. 6: 32653274 .

Potter, L. T. (1967) A radiometric microassay of acetylcholinesterase. J. Pharmacol. Exp. Ther. 156: 500-506.

Radeke, M. J., T. P. Misko, C. Hsu, L. A. Herzenberg, and E. M. Shooter (1987) Gene transfer and molecular cloning of the rat nerve growth factor receptor. Nature 325: 593-597.

Richardson, P. M., V. M. K. Verge Issa, and R. J. Riopelle (1986) Distribution of neuronal receptors for nerve growth factor in the rat. J. Neurosci. 6: 2312-2321.

Rohrer, H., and Y. A. Barde (1982) Presence and disappearance of nerve growth factor receptors on sensory neurons in culture. Dev. Biol. 89: 309-315.

Ruegg, U. T., and F. Hefti (1984) Growth of dissociated neurons in culture dishes coated with synthetic polymeric amines. Neurosci. Lett. 49: 319-324.

Schnaar, R. L., and A. E. Schaffner (1981) Separation of cell types from embryonic chicken and rat spinal cord: Characterization of motoneuron enriched fractions. J. Neurosci. 1: 204-217.

Schwab, M. E., U. Otten, Y. Agid, and H. Thoenen (1979) Nerve growth factor (NGF) in the rat CNS: Absence of specific retrograde axonal transport and tyrosine hydroxylase induction in locus coeruleus and substantia nigra. Brain Res. 168: 473-483.

Seiler, M., and M. E. Schwab (1984) Specific retrograde transport of nerve growth factor (NGF) from ncocortex to nuclcus basalis in the rat. Brain Res. 300: 33-39.

Shelton, D. L., and L. F. Reichardt (1986) Studies on the expression of the beta nerve growth factor (NGF) gene in the central nervous system: Level and regional distribution of NGF mRNA suggest that NGF functions as a trophic factor for several distinct populations of neurons. Proc. Natl. Acad. Sci. USA 83: 2714-2718.

Springer, J. E., and R. Loy (1985) Intrahippocampal injections of antiserum to nerve growth factor inhibit sympato-hippocampal sprouting. Brain Res. Bull. 15: 629-634.

Springer, J. E., S. Koh, M. W. Tayrien, and R. Loy (1987) Basal forebrain magnocellular neurons stain for nerve growth factor receptor: Correlation with cholinergic cell bodies and effects of axotomy. J. Neurosci. Res. 17: 111-118.

Suda, K., Y. A. Barde, and H. Thoenen (1978) Nerve grewth factor in mouse and rat serum: Correlation between bioassay and radioimmunoassay determinations. Proc. Natl. Acad. Sci. USA 75: 40424046.

Taniuchi, M., and E. M. Johnson (1985) Characterization of the binding properties and retrograde transport of a monoclonal antibody directed against the rat nerve growth factor receptor. J. Cell Biol. 101: 1100-1106.

Taniuchi, M., J. B. Schweitzer, and E. M. Johnson (1986) Demonstration of nerve growth factor receptor in the rat brain. Proc. Natl. Acad. Sci. USA 83: 4094-4098.

Thoenen, H., and Y. A. Barde (1980) Physiology of nerve growth factor. Physiol. Rev. 60: 1284-1335.

Thoenen, H., and D. Edgar (1985) Neurotrophic factors. Science 229: 238-242.

Wainer, B. H., A. I. Levey, E. F. Mufson, and M. M. Mesulam (1984) Cholinergic systems in mammalian brain identified with antibodies against choline acetyltransferase. Neurosci. Int. 6: 163-182. 
Whittemore, S. R., T. Ebendal, L. Lärkfors, L. Olson, A. Seiger, I. Stromber, and H. Persson (1986) Developmental and regional expression of beta nerve growth factor messenger RNA and protein in the rat central nervous system. Proc. Natl. Acad. Sci. USA 83: 817-821.

Whittemore, S. K., L. Lärkfors, T. Ebendal, V. R. Holets, A. Ericsson, and $H$. Persson (1987) Increased $\beta$-nerve growth factor messenger RNA and protein levels in neonatal rat hippocampus following specific cholinergic lesions. J. Neurosci. 7: 244-251.
Williams, L. R, S. Varon, G. M. Peterson, K. Wictorin, W. Fischer, A. Björklund, and F. H. Gage (1986) Continuous infusion of nerve growth factor prevents basal forebrain neuronal dcath after fimbria fornix transection. Proc. Natl. Acad. Sci. USA 83: 9231-9235.

Woolf, N. J., F. Eckenstein, and L. L. Butcher (1984) Cholinergic systems in the rat brain: I. Projections to the limbic telencephalon. Brain Res. Bull. 13: 751-784.

Yankner, B. A., and E. M. Shooter (1982) The biology and mechanism of action of nerve growth factor. Annu. Rev. Biochem. 51: 845-868. 